\title{
1 Engineered Enzymes that Retain and Regenerate their Cofactors Enable Continuous-Flow \\ 2 Biocatalysis
}

3 Carol J. Hartley ${ }^{1}$, Charlotte C. Williams ${ }^{2}$, Judith A. Scoble ${ }^{2}$, Quentin I. Churches ${ }^{2}$, Andrea North ${ }^{2}$, Nigel

4 G. French ${ }^{1}$, Tom Nebl ${ }^{2}$, Greg $\mathrm{Coia}^{2}$, Andrew C. Warden ${ }^{1}$, Greg Simpson ${ }^{3}$ Andrew R. Frazer ${ }^{3}$, Chantel

5 Nixon Jensen ${ }^{4}$, Nicholas J. Turner ${ }^{4}$, Colin Scott ${ }^{1}$.

$6 \quad{ }^{1}$ Biotechnology and Synthetic Biology Group, CSIRO Land \& Water, Black Mountain Science \&

7 Innovation Precinct, Canberra, Australia

$8 \quad{ }^{2}$ CSIRO Manufacturing, 343 Royal Parade, Parkville, Victoria 3052, Australia

$9 \quad{ }^{3}$ CSIRO Manufacturing, Bag 10, Bayview Avenue, Clayton, Victoria 3168, Australia

$10{ }^{4}$ School of Chemistry, Manchester Institute of Biotechnology, University of Manchester, UK

12 Keywords: nanomachines, nanofactory, biocatalysis, continuous flow biocatalysis, synthetic biology, 13 glycerol kinase, glycerol-3-phosphate dehydrogenase, aldolase, reactor, enzyme immobilization, D14 fagomine, cofactor immobilization, cofactor recycling.

15 For correspondence email: $\underline{\text { colin.scott@ csiro.au }}$ 


\section{Introduction}

Biocatalysis is used for many chemical syntheses due to its high catalytic rates, specificities and operation under ambient conditions 1,2. Continuous-flow chemistry offers advantages to biocatalysis, avoiding process issues caused by substrate/product inhibition, equilibrium controlled limitations on yield and allosteric control ${ }^{3}$. Modular continuous-flow biochemistry would also allow the flexible assembly of different complex multistep reactions ${ }^{3-6}$. Here we tackle some technical challenges that currently prohibit the wide-spread use of continuous flow biocatalysis; cofactor immobilization and site-specific immobilization. We provide the first example of enzymes engineered to retain and recycle their cofactors, and the use of these enzymes in continuous production of chiral pharmaceutical intermediates.

Enzyme immobilization for continuous-flow applications has been studied for some time; indeed, a number of industrial processes are currently based on such technologies ${ }^{4,6-10}$. However, such processes have generally been limited to cofactor-independent enzymes, such as esterases. Cofactors, such as nicotinamide adenine dinucleotide $\left(\mathrm{NAD}^{+}\right)$and adenosine triphosphate (ATP), are used stoichiometrically unless recycled, typically by a second enzyme: without recycling, cofactors become prohibitively expensive for most industrial syntheses. As cofactors require diffusion for recycling, they are ill-suited for use in continuous-flow reactors and the lack of a practical engineering solution for the issue has stymied the use of cofactor-dependent enzymes in continuous-flow applications ${ }^{4}$; although, growing interest in immobilized biocatalysts for cell-free metabolic engineering has led to the development of a variety of enzyme-cofactor-carrier combinations ${ }^{5}$.

Herein, we propose a novel and generalizable chemo-genetic enzyme engineering approach that enables the fabrication of modular, multistep, biocatalytic, continuous-flow reactors using cofactordependent enzymes, thereby extending the utility of biocatalysis for continuous-flow production systems and cell-free metabolic engineering ${ }^{11}$.

\section{Results}

\section{Nanomachine design}

Our design for a biocatalyst that can retain and recycle its cofactor (a 'nanomachine') was inspired by enzymes that retain their substrates via covalent attachment during a reaction cascade involving multiple active sites, e.g. phosphopantetheine-dependent synthases ${ }^{12-14}$ and lipoic acid-dependent dehydrogenases ${ }^{15}$. In such enzymes, the substrate is delivered from one active site to the next by a 
flexible 'swinging arm' that is covalently attached to the protein. We have adopted a similar strategy, whereby a flexible swinging arm covalently attaches a cofactor to a synthetic, multidomain protein and delivers that cofactor to the different active sites of the fusion protein, allowing its simultaneous use and recycling, while preventing its diffusion (Figure 1).

The general design of our nanomachines is shown in Figure 1. Each nanomachine is comprised of three modules: a catalytic module that drives the desired synthesis reaction, a cofactor recycling module that regenerates the cofactor after use, and an immobilization module that allows site-specific, covalent conjugation to an activated surface. The modular design is intended to allow a small number of immobilization and cofactor recycling modules to be used with a wide variety of synthesis modules, thereby enabling diverse synthetic reactions using a relatively small library of core nanomachine components. It is envisaged that multiple nanomachines could be combined in series or in networks to produce a 'nanofactory' for the synthesis of complex chiral molecules using multi-enzyme cascade reactions.

In our design, the three modules of each nanomachine were encoded by a single gene for production in E. coli as a single protein with a short spacer (2-20 amino acids, Online methods) separating each module. A modified cofactor was designed that could be conjugated to the spacer between the catalytic and cofactor recycling modules. We used a maleimide-functionalized polyethylene glycol (PEG) for the flexible linker to allow movement of the modified cofactor between active sites. In silico modelling suggested that a chain length of twenty-four ethylene glycol units was long enough to allow ingress into both active sites. The amino acid spacer that separated the catalytic and cofactor recycling modules contained a single solvent exposed cysteine residue, which provided an accessible thiol group with which to tether the maleimide-functionalized PEGylated cofactor (Figure 1).

\section{Assembling the nanomachines}

For the prototype nanofactory we selected D-fagomine synthesis - coupling three nanomachines in series to convert glycerol (1) and 3-aminopropanal (3) into a chiral drug precursor (Figure 2). Total synthesis of this anti-diabetic piperidine iminosugar using non-biological catalysts is challenging, due to the complexity conferred by its two stereocenters, and eight possible diastereomers, with even recent advances only resulting in yields up to $65 \%$ of each diastereomer ${ }^{16}$. In our nanofactory (a cascade of nanomachines), glycerol is converted to dihydroxyacetone phosphate (DHAP) (4) by regiospecific phosphorylation and oxidation, via ATP and NAD+-dependent steps, respectively. A subsequent aldolase-catalyzed stereoselective aldol addition with 3-aminopropanal yields $(3 S, 4 R)$ - 
amino-3,4-dihydroxy-2-oxyhexyl phosphate (3S,4R-ADHOP), which can be dephosphorylated with phosphorylase and cyclized to form D-fagomine ${ }^{17}(6)$. For the purposes of purification, we elected to use the carboxybenzyl (Cbz)-protected derivative of 3-aminopropanal, yielding $\mathrm{N}$-Cbz-3S,4R-ADHOP (5).

Prior comparison of enzymes that could be used for the first two steps of the model synthesis ${ }^{18}$ had suggested that the most suitable enzymes for glycerol phosphorylation were a Thermococcus kodakarensis glycerol kinase $\left(\mathrm{GlpK}_{\mathrm{TK}}\right)$ and a Mycobacterium smegmatis acetate kinase (AceK $\left.\mathrm{M}_{\mathrm{MS}}\right)$. For the NAD+-dependent production of DHAP from glycerol-3-phosphate (G3P), E. coli glycerol-3phosphate dehydrogenase $\left(G 3 P D_{E C}\right)$ and the water-forming $\mathrm{NADH}$ oxidase from Clostridium aminovalericum ( $\mathrm{NOX}_{\mathrm{C}_{\mathrm{a}}}$ ) were selected. The third reaction step is a cofactor-independent aldolasecatalyzed aldol addition. A monomeric fructose aldolase (FruA) homolog from Staphylococcus carnosus was selected from a panel of five potential aldolases. Each of the enzymes incorporated into the nanomachine fusion proteins were selected for their compatibility in batch reactions ${ }^{18}$, high catalytic rates, relatively simple quaternary structures and thermostability (Supplementary Table 2).

For the conjugation module, we used a serine hydrolase enzyme coupled with a suicide inhibitor (trifluoroketone, TFK) that forms a site-specific and stable covalent bond between the inhibitor and the catalytic serine residue ${ }^{19}$. Esterase E2 from Alicyclobacillus acidocaldarius $\left(E 2_{\mathrm{Aa}}\right){ }^{20}$ was selected for the serine hydrolase component as a highly stable, soluble, monomeric protein (Supplementary Table 2).

The genes encoding $\mathrm{GlpK}_{\mathrm{Tk}}$ and $\mathrm{AceK}_{\mathrm{Ms}}$ were fused, such that $\mathrm{GlpK}_{\mathrm{Tk}}$ formed the N-terminus of the resultant protein and AceK $_{\text {Ms }}$ formed the C-terminus (Fig. 2). The two modules were separated by a nineteen amino acid unstructured amino acid linker, containing a single, solvent-accessible cysteine residue that was used subsequently as the attachment point for the maleimide functionalized $\mathrm{PEG}_{24}{ }^{-}$ ATP ([GSS $\left.]_{3} C[G S S]_{3}\right)$. A similar gene fusion was constructed used $G_{3 P D_{E c}}$ and $N O X_{c a}$, producing a protein in which $\mathrm{G}_{3} \mathrm{PD}_{\mathrm{EC}}$ formed the N-terminus and $\mathrm{NOX}_{\mathrm{Ca}}$ formed the $\mathrm{C}$-terminus. The fused proteins retained or in some cases improved their original catalytic functions (Table 1), albeit some loss of activity (both $K_{\mathrm{M}}$ and $k_{\text {cat }}$ ) was incurred for $A c e K_{\mathrm{Ms}}$ and $\mathrm{G} \mathrm{PD}_{\mathrm{Ec}}$. The thermal stability of each of the fused enzymes appeared to be independent of one another i.e. protein unfolding of the component modules of each fusion are independent events (Supplementary Table 2).

The gene encoding the conjugation module (E2 $2_{\mathrm{Aa}}$ ) was fused with both the $g / p K_{T K}-a c e K_{M s}$ and $g 3 p D_{E c^{-}}$ nox $x_{C a}$ such that it formed the C-terminus of the encoded proteins (i.e., $\mathrm{GlpK}_{\mathrm{TK}}-\mathrm{AceK}_{\mathrm{Ms}}-\mathrm{E}_{\mathrm{Aa}}$ and $\mathrm{G} \mathrm{PD}_{\mathrm{Ec}}{ }^{-}$ NOX $\left.\mathrm{Ca}_{\mathrm{C}}-\mathrm{E} 2_{\mathrm{Aa}}\right)$. Addition of the conjugation module had little effect on the kinetic performance or thermal stabilities of the other modules of each nanomachine (Table 1 \& Supplementary Table 1 ). The 
conjugation module was highly efficient (86-98\% immobilization efficiency), and the immobilized enzymes retained their activity. This immobilization technique has the potential for broad applicability to other biocatalytic systems.

The cofactors were modified (Online methods) by functionalization of the C6-adenine-amine of ADP (7) or $\mathrm{NAD}^{+}$(12) to which a modified $\mathrm{PEG}_{24}$ was added (Fig. 1; Supplementary Scheme 1). The $\mathrm{PEG}_{24}$ linker included an $\mathrm{N}$-hydroxysuccinimide ester that allowed reaction with the modified cofactor and a maleimide group for conjugation with the fusion proteins. Conjugation of MAL-PEG $24-2 A E-A D P$ (11) and MAL-PEG ${ }_{24}-2 A E-N A D^{+}(13)$ to the nanomachines yielded enzymes that were active in batch reactions without the addition of exogenous cofactor, with catalytic constants equivalent or superior to individual enzyme components (Table 1; Supplementary Figure 3). Mass spectrometry of cofactorconjugated proteolyzed nanomachines indicated that the cysteine in the linker between the catalytic and cofactor recycling modules reacted preferentially with the $\mathrm{PEG}_{24}$-maleimide modified cofactors (Supplementary Figure 4). Between $80-100 \%$ of the target cysteine residue was conjugated with the modified cofactor for both nanomachines.

\section{Function of Nanofactory}

The nanomachines were immobilized on TFK-activated agarose beads at densities of 1.6, 1.0 and 1.0 milligrams protein per gram wet beads for the phosphorylation, oxidation and aldolase nanomachines, respectively, and packed into glass columns to produce three nanomachine packed bed reactor columns: a phosphorylation column ( $23.1 \mathrm{~mL}$ packed volume), an oxidation column ( $25.7 \mathrm{~mL}$ packed volume) and an aldol addition column (17.7 mL packed volume) (Figure 2).

Individual performance data for each nanomachine reactor (Figure 3) revealed that the maximum space time yields obtained ranged from $\sim 11 \mathrm{mg} \mathrm{L}^{-1} \mathrm{~h}^{-1} \mathrm{mg}^{-1}$ (mg product per mg protein per liter per hour) for the oxidation reactor to $70 \mathrm{mg} \mathrm{L}^{-1} \mathrm{~h}^{-1} \mathrm{mg}^{-1}$ for the phosphorylation reactor, with the aldol addition reactor yielding $\sim 30 \mathrm{mg} \mathrm{L}^{-1} \mathrm{~h}^{-1} \mathrm{mg}^{-1}$. This is consistent with the expected yields based on $k_{\mathrm{cat}} / K_{\mathrm{M}}$ values of the loaded enzymes (Table 1), e.g., for the phosphorylation reactor, $36.9 \mathrm{mg}$ protein per column ( $2.7 \mathrm{nmol}$ tethered biocatalysts) yielded $2.6 \mathrm{~g}$ product per litre $(6.6 \mathrm{mM})$ per hour, equivalent to the expected $1,399 \mathrm{nmol}$ per nmol of enzyme per second.

As reported elsewhere, when the glycerol-3-phosphate oxidation reaction and aldolase reaction were run in batch, yields were limited by product inhibition and substrate: product equilibrium, with substrate conversion of $88 \%$ and $63 \%$ respectively $18,21,22$. In our reactors, the phosphorylation and oxidation reactions were run to completion (i.e., complete $100 \%$ substrate conversion). It is likely that 
running the system as a continuous flow reaction prevented the build-up of reaction products and so mitigated both product inhibition and equilibrium control, resulting in the high yields observed in our reactors.

The turnover numbers for the cofactors exceeded 10,000 ( 11,000 for the NAD+-dependant oxidation reactor and 17,000 for the ATP-dependant phosphorylation reactor; Figure 3a). In each case the reactions stopped because of the inactivation of one of the modules (AceK $\mathrm{MS}_{\mathrm{s}}$ for the phosphotransfer reactor; NOX $\mathrm{Ca}_{\mathrm{a}}$ for the oxidation reactor) rather than the loss of cofactor. It is reasonable to assume that the turnover numbers would be higher if the enzymes were modified for greater stability, a relatively facile exercise with modern enzyme engineering approaches ${ }^{23,} 24$.

The three reactors were then combined in series (Figure $2 \mathrm{~b}$ ), with glycerol fed to the first reactor (the phosphorylation reactor) and a feed of Cbz-protected aldehyde entering the system between the oxidation and aldol addition reactors, to yield a three component 'nanofactory' for the production of Cbz-protected chiral sugar phosphates from glycerol. When run at $0.3 \mathrm{~mL}$ per minute, over $80 \%$ of glycerol was converted to enantiomerically pure $\mathrm{N}-\mathrm{Cbz}-3 \mathrm{~S}, 4 R-\mathrm{ADHOP}$ in a single passage through the reactor (the product was confirmed by HPLC, LCMS and ${ }^{1} \mathrm{H}$ NMR analysis; Supplementary Figure 6). The percent conversion dropped to $40 \%$ at higher flow rates $\left(1.0 \mathrm{~mL} \cdot \mathrm{min}^{-1}\right)$, albeit this could be improved through reactor engineering (longer columns, greater biocatalyst loading, multiple passages through the reactor, etc.).

\section{Conclusions}

We have developed and successfully implemented a general chemo-genetic protein engineering strategy that enables cofactor-dependent, continuous-flow biocatalysis via the use of nanomachines: single molecule multi-enzyme biocatalysts that retain and recycle their cofactors. The engineered biocatalysts were used to construct a three step continuous-flow reactor system (a 'nanofactory') that performed well, with superior yields of D-fagomine precursor compared to chemical syntheses ${ }^{16}$, as well as high space-time yields and total turnover numbers for the catalysts and cofactors. Additionally, use of the biocatalysts in a continuous-flow system appears to have mitigated production inhibition and equilibrium control of yield, allowing very high substrate conversion.

We have used sugar analog synthesis as a model for our prototype 'nanofactory'; however, we believe that this approach is generalizable because of the modular design principles used in the design of both the 'nanomachines' and the 'nanofactories'. For the nanomachines, we envision a small library of conjugation and cofactor recycling modules that could be used in conjunction with a larger library of 
to demonstrate stereoselective aldol addition with the fructose-1,6-biphosphate aldolase FruA, use of the three other classes of DHAP-dependant aldolases (fuculose-1-phosphate FucA, rhamnulose-1phosphate aldolase RhuA, tagatose-1,6-biphosphate aldolase TagA) ${ }^{22}$ for the aldol addition reactor could be employed to generate all four ADHOP diastereomers with simple flow-path changes. The molecular modularity of the nanomachines is mirrored in the flow reactor design, providing a flexible platform for building complex, multistep biochemical pathways with both serial and parallel reactor compartments that could be extended into the development of artificial metabolic networks.

\section{Acknowledgements}

We would like to acknowledge the Science and Industry Endowment Fund (SIEF) for funding this work. We would like to thank Drs Matthew Wilding (Australian National University) and John Oakeshott (CSIRO) for their constructive comments during the preparation of this manuscript.

\section{Author Contributions}

$\mathrm{CH}, \mathrm{CS}, \mathrm{CW}, \mathrm{NT}, \mathrm{JS}, \mathrm{GS}, \mathrm{GC}$ conceived and designed the study. $\mathrm{CH}, \mathrm{JS}, \mathrm{CW}, \mathrm{NF}, \mathrm{QI}, \mathrm{AN}, \mathrm{AF}, \mathrm{TN}, \mathrm{CN}-\mathrm{J}$ performed experiments. $\mathrm{CH}, \mathrm{CW}, \mathrm{JS}, \mathrm{AF}, \mathrm{AN}, \mathrm{TN}, \mathrm{QI}, \mathrm{CN}-\mathrm{J}$ analyzed data and $\mathrm{AW}$ performed computational modelling analysis. $\mathrm{CH}, \mathrm{CW}, \mathrm{AN}, \mathrm{JS}, \mathrm{NF}, \mathrm{TN}$ and $\mathrm{CS}$ wrote the paper.

\section{Competing Interests Statement}

The authors have submitted a PCT Patent Application (WO 2017_011870_A1) based on the research results reported in this paper.

\section{References:}

1. Turner, N.J. \& O'Reilly, E. Biocatalytic retrosynthesis. Nature Chemical Biology 9, 285-288 (2013).

2. Wells, A. \& Meyer, H.-P. Biocatalysis as a Strategic Green Technology for the Chemical Industry. ChemCatChem 6, 918-920 (2014).

3. Gandomkar, S., Żądło-Dobrowolska, A. \& Kroutil, W. Extending Designed Linear Biocatalytic Cascades for Organic Synthesis. ChemCatChem 11, 225-243 (2019). 
bioRxiv preprint doi: https://doi.org/10.1101/568972; this version posted March 5, 2019. The copyright holder for this preprint (which was not certified by peer review) is the author/funder, who has granted bioRxiv a license to display the preprint in perpetuity. It is made available under aCC-BY-NC-ND 4.0 International license.

4. Tamborini, L., Fernandes, P., Paradisi, F. \& Molinari, F. Flow Bioreactors as Complementary Tools for Biocatalytic Process Intensification. Trends in Biotechnology (2017).

5. López-Gallego, F., Jackson, E. \& Betancor, L. Heterogeneous Systems Biocatalysis: The Path to the Fabrication of Self-Sufficient Artificial Metabolic Cells. Chemistry - A European Journal 23, 17841-17849 (2017).

6. Britton, J., Majumdar, S. \& Weiss, G.A. Continuous flow biocatalysis. Chemical Society Reviews (2018).

7. Zhang, Y.-H.P., Sun, J. \& Ma, Y. Biomanufacturing: history and perspective. Journal of Industrial Microbiology \& Biotechnology, 1-12 (2016).

8. Santacoloma, P.A. \& Woodley, J.M. in Cascade Biocatalysis 231-248 (Wiley-VCH Verlag GmbH \& Co. KGaA, 2014).

9. Weiser, D. et al. in Biocatalysis: An Industrial Perspective 397-430 (The Royal Society of Chemistry, 2018).

10. Thompson, M.P., Peñafiel, I., Cosgrove, S.C. \& Turner, N.J. Biocatalysis Using Immobilized Enzymes in Continuous Flow for the Synthesis of Fine Chemicals. Organic Process Research \& Development 23, 9-18 (2019).

11. Dudley, Q.M., Karim, A.S. \& Jewett, M.C. Cell-free metabolic engineering: Biomanufacturing beyond the cell. Biotechnology Journal 10, 69-82 (2015).

12. Keatinge-Clay, A.T. Stereocontrol within polyketide assembly lines. Nat. Prod. Rep. 33, 141149 (2016).

13. Dutta, S. et al. Structure of a modular polyketide synthase. Nature 510, 512-517 (2014).

14. Nguyen, C. et al. Trapping the dynamic acyl carrier protein in fatty acid biosynthesis. Nature 505, 427-431 (2014).

15. Cronan, J.E., Zhao, X. \& Jiang, Y.F. in Advances in Microbial Physiology, Vol 50, Vol. 50. (ed. R.K. Poole) 103-146 (2005).

16. Davies, S.G., Fletcher, A.M., Kennedy, M.S., Roberts, P.M. \& Thomson, J.E. Asymmetric synthesis of d-fagomine and its diastereoisomers. Tetrahedron 74, 7261-7271 (2018).

17. Castillo, J.A. et al. Fructose-6-phosphate Aldolase in Organic Synthesis: Preparation of dFagomine, N-Alkylated Derivatives, and Preliminary Biological Assays. Organic Letters 8, 60676070 (2006).

18. Hartley, C.J. et al. Sugar analog synthesis by in vitro biocatalytic cascade: A comparison of alternative enzyme complements for dihydroxyacetone phosphate production as a precursor to rare chiral sugar synthesis. Plos One 12 (2017).

19. Minařik, A. et al. Ligand-Directed Immobilization of Proteins through an Esterase 2 Fusion Tag Studied by Atomic Force Microscopy. ChemBioChem 9, 124-130 (2008).

20. Huang, Y., Humenik, M. \& Sprinzl, M. Esterase 2 from Alicyclobacillus acidocaldarius as a reporter and affinity tag for expression and single step purification of polypeptides. Protein Expression and Purification 54, 94-100 (2007).

21. Wang, W., Liu, M., You, C., Li, Z. \& Zhang, Y.-H.P. ATP-free biosynthesis of a high-energy phosphate metabolite fructose 1,6-diphosphate by in vitro metabolic engineering. Metabolic Engineering 42, 168-174 (2017).

22. Schumperli, M., Pellaux, R. \& Panke, S. Chemical and enzymatic routes to dihydroxyacetone phosphate. Appl Microbiol Biotechnol 75, 33-45 (2007).

23. Jemli, S., Ayadi-Zouari, D., Hlima, H.B. \& Bejar, S. Biocatalysts: application and engineering for industrial purposes. Crit. Rev. Biotechnol. 36, 246-258 (2016).

24. Modarres, H.P., Mofrad, M.R. \& Sanati-Nezhad, A. Protein thermostability engineering. RSC Advances 6, 115252-115270 (2016).

25. Hartley, C.J. et al. Sugar analog synthesis by in vitro biocatalytic cascade: A comparison of alternative enzyme complements for dihydroxyacetone phosphate production as a precursor to rare chiral sugar synthesis. PLOS ONE 12, e0184183 (2017). 
bioRxiv preprint doi: https://doi.org/10.1101/568972; this version posted March 5, 2019. The copyright holder for this preprint (which was not certified by peer review) is the author/funder, who has granted bioRxiv a license to display the preprint in perpetuity. It is made available under aCC-BY-NC-ND 4.0 International license.

26. Peat, T.S. et al. Cyanuric acid hydrolase: evolutionary innovation by structural concatenation. Molecular microbiology 88, 1149-1163 (2013).

27. Koga, Y. et al. Thermostable glycerol kinase from a hyperthermophilic archaeon: gene cloning and characterization of the recombinant enzyme. Protein Engineering 11, 1219-1227 (1998).

28. Aceti, D.J. \& Ferry, J.G. Purification and characterization of acetate kinase from acetate-grown Methanosarcina thermophila. Evidence for regulation of synthesis. Journal of Biological Chemistry 263, 15444-15448 (1988).

29. Kawasaki, S., Ishikura, J., Chiba, D., Nishino, T. \& Niimura, Y. Purification and characterization of an $\mathrm{H}_{2} \mathrm{O}$-forming $\mathrm{NADH}$ oxidase from Clostridium aminovalericum: existence of an oxygendetoxifying enzyme in an obligate anaerobic bacteria. Archives of Microbiology 181, 324-330 (2004).

30. Brockamp, H.P. \& Kula, M.R. Purification and characterization of a class I fructose 1,6bisphosphate aldolase from Staphylococcus carnosus. Applied Microbiology and Biotechnology 34, 287-291 (1990).

31. Manco, G. et al. Overexpression and properties of a new thermophilic and thermostable esterase from Bacillus acidocaldarius with sequence similarity to hormone-sensitive lipase subfamily. The Biochemical journal 332 ( Pt 1), 203-212 (1998).

32. Prieto-Blanco, M.C., Iglesias, M.P., López-Mahía, P., Lorenzo, S.M. \& Rodríguez, D.P. Simultaneous determination of carbonyl compounds and polycyclic aromatic hydrocarbons in atmospheric particulate matter by liquid chromatography-diode array detectionfluorescence detection. Talanta 80, 2083-2092 (2010). 


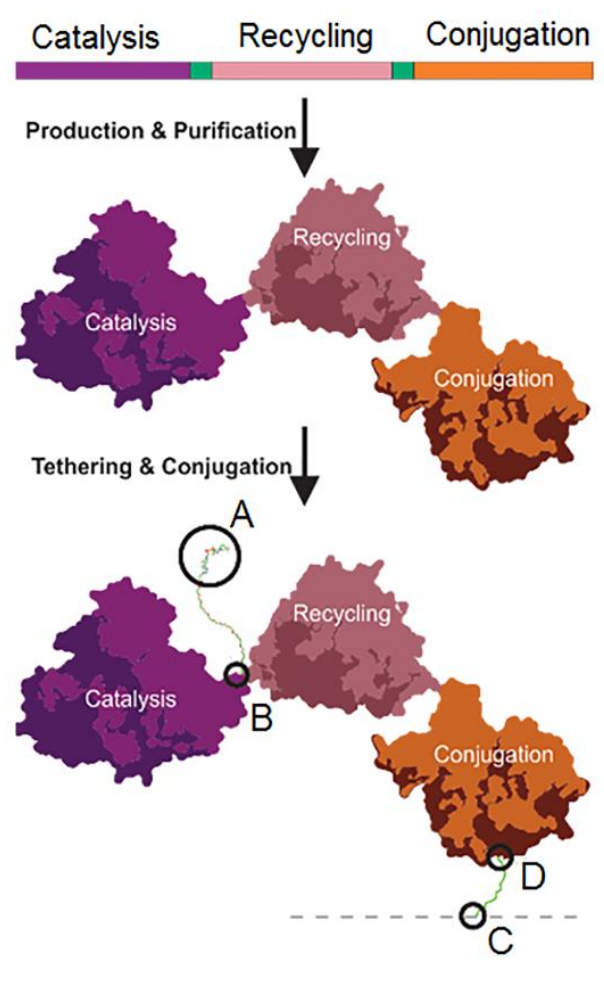

282

283

.

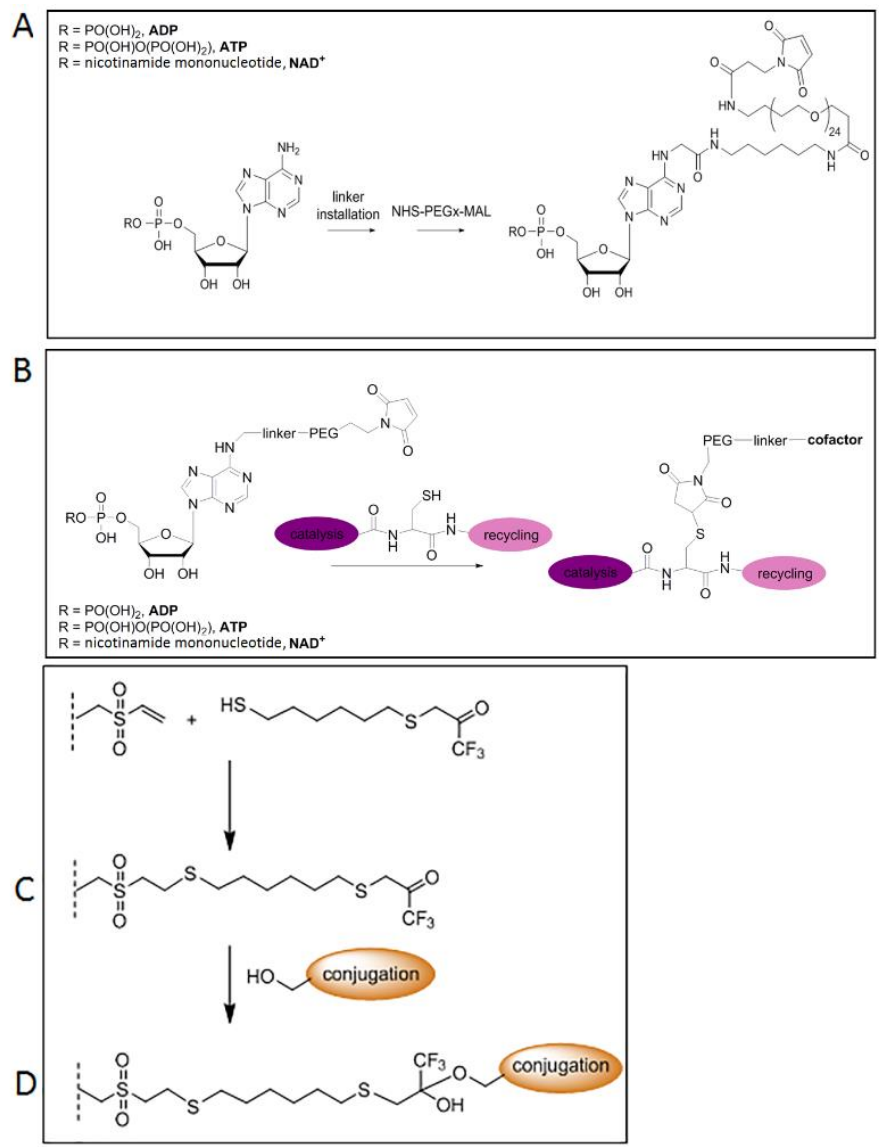

Fig. 1. Nanomachine design. Each nanomachine comprises a genetically encoded multi-enzyme fusion protein capable of retaining and recycling a tethered cofactor. The nanomachine contains three protein domains: a cofactor-dependant catalytic enzyme domain (purple), a cofactor-recycling domain (pink) with short amino acid spacer regions between these domains (see Online Methods for details) A cofactor that has been modified by amine activation to allow for linker installation $(\mathbf{A})$ is tethered to the protein through maleimide: thiol conjugation via a solvent exposed cysteine located in the spacer region between the catalysis and recycling domains (B). The esterase conjugation domain (orange) allows immobilization of the nanomachine to a surface by the formation of a covalent bond between a surface attached trifluoroketone (C) and the active site serine of the esterase (D). 
a

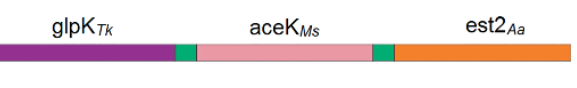

$\operatorname{gps} \mathrm{A}_{E C}$

$\operatorname{nox}_{\mathrm{Ca}}$

est2 $A a$

fruAsc

est2 ${ }_{A a}$ b

\section{Phosphotransfer \\ Reactor}

Oxidation Reactor

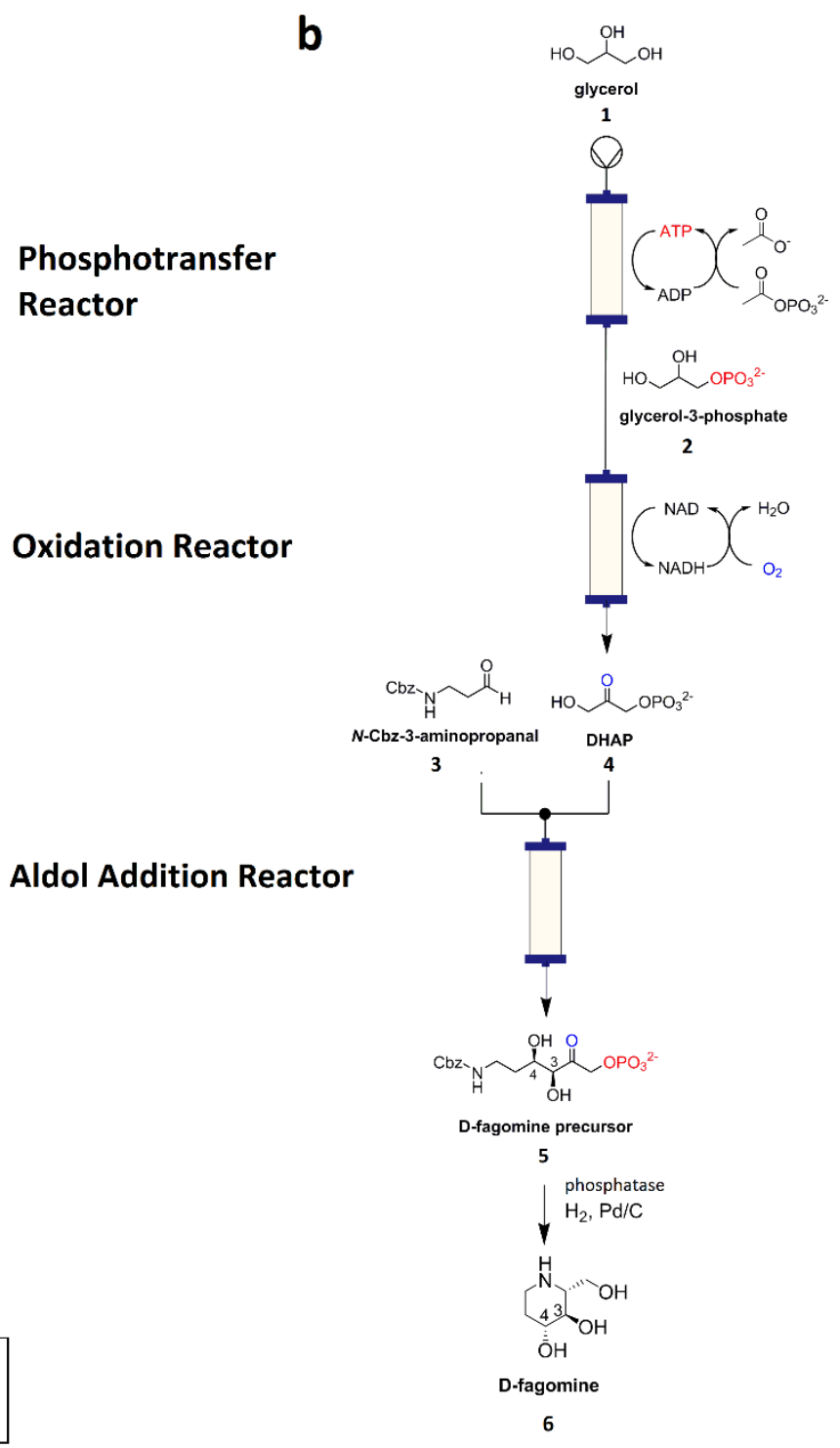

Aldol Addition Reactor
297

KEY: Catalysis Cofactor Recycling Conjugation

298

Figure 2. Nanofactory design for the conversion of glycerol to a chiral D-fagomine precursor. a,

299

Composition of the three nanomachines each comprising a cofactor-dependant catalytic enzyme

300 domain (purple), a cofactor-recycling domain (pink) and the conjugation domain (orange), with amino acid spacer regions between these domains (green). b. Corresponding three part nanofactory and associated biotransformations (phosphotransfer, oxidation and aldol addition) for D-fagomine synthesis. Enzyme name abbreviations are as defined in the text. 
a

\begin{tabular}{|c|c|c|c|c|c|}
\hline Nanomachine & $\begin{array}{l}\text { Flow rate } \\
\left(\mathrm{mL} \min ^{-1}\right)\end{array}$ & $\begin{array}{c}R_{\mathrm{t}} \\
(\mathrm{min})\end{array}$ & $\begin{array}{l}\text { Product } \\
\text { Yield } \\
(\mathrm{mmol})\end{array}$ & $\begin{array}{c}\text { Total } \\
\text { Turnover } \\
\text { Number } \\
\text { (cofactor) }\end{array}$ & $\begin{array}{c}\text { Space Time } \\
\text { Yield } \\
\left(\mathrm{g} \mathrm{L}^{-1} \mathrm{hr}^{-1} \mathrm{~g}^{-1}\right)\end{array}$ \\
\hline 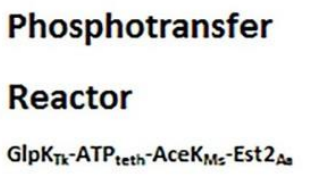 & 0.25 & 84.8 & 1.17 & 16848 & 69.95 \\
\hline $\begin{array}{l}\text { Oxidation Reactor } \\
G 3 P D_{E-C}-N A D_{t e t e n}-N O X_{C_{0}}-E s t 2_{A 0}\end{array}$ & 0.25 & 113.2 & 0.95 & 10839 & 10.75 \\
\hline $\begin{array}{l}\text { Aldol Addition } \\
\text { Reactor } \\
\text { FruA }_{\text {sc-Est2 } 2}\end{array}$ & 0.1 & 177 & 4.67 & NA & 28.58 \\
\hline
\end{tabular}

b

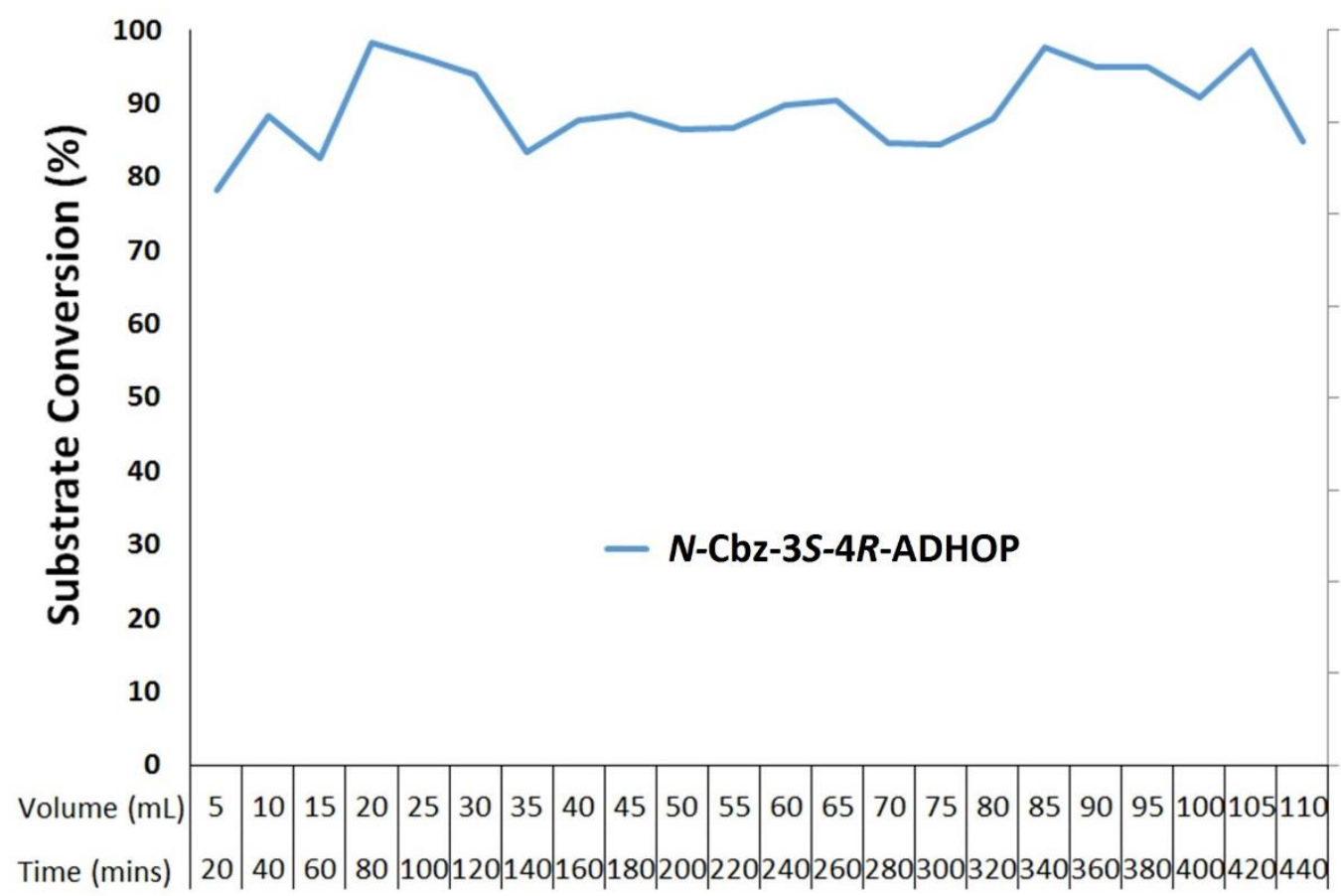

4.00

3.50

3.00

2.50

2.00

1.50

Figure 3. Functional analysis of the three-step nanofactory for the synthesis of D-fagomine from

glycerol. a, Product yield, cofactor total turnover numbers and space-time yield metrics for each ADHOP) for more than $7 \mathrm{~h}$. 
Table 1. Steady-state kinetic data for the enzymes comprising each nanomachine.

\begin{tabular}{|c|c|c|c|c|}
\hline & $\begin{array}{l}K_{\mathrm{M}} \\
(\mu \mathrm{M})\end{array}$ & $\begin{array}{l}K_{\mathrm{M}} \\
(\mu \mathrm{M})\end{array}$ & $\begin{array}{l}k_{\mathrm{cat}} \\
\left(\mathrm{s}^{-1}\right)\end{array}$ & $\begin{array}{l}k_{\mathrm{cat}} / K_{\mathrm{M}} \\
\left(\mathrm{s}^{-1} \cdot \mathrm{M}^{-1}\right)\end{array}$ \\
\hline & Cofactor & Substrate & & \\
\hline \multicolumn{5}{|l|}{ Glycerol phosphorylation } \\
\hline $\mathrm{GlpK}_{T K}$ & $111 \pm 12$ & $15 \pm 2$ & $940 \pm 8$ & $6.1 \times 10^{7}$ \\
\hline $\mathrm{GlpK}_{\mathrm{TK}}-\mathrm{AceK}_{\mathrm{Ms}}$ & $123 \pm 21$ & $15 \pm 4$ & $1,125 \pm 115$ & $7.7 \times 10^{7}$ \\
\hline $\mathrm{GlpK}_{\mathrm{TK}}-\mathrm{AceK}_{\mathrm{Ms}}-\mathrm{Est}_{\mathrm{Aa}}$ & $115 \pm 19$ & $16 \pm 4$ & $1,399 \pm 54$ & $8.6 \times 10^{7}$ \\
\hline GlpK $_{\text {TK}}-A T P_{\text {teth }}-A_{c e} K_{M s}-E s t 2_{\mathrm{Aa}}$ & ND & $16 \pm 2$ & $1,408 \pm 95$ & $8.8 \times 10^{7}$ \\
\hline
\end{tabular}

\section{Acetate dephosphorylation (ADP phosphorylation)}

\begin{tabular}{|c|c|c|c|c|}
\hline AceK $_{M s}$ & $113 \pm 9$ & $390 \pm 8$ & $1,103 \pm 126$ & $2.8 \times 10^{6}$ \\
\hline $\mathrm{GlpK}_{\mathrm{Tk}}-\mathrm{AceK}_{\mathrm{Ms}}$ & $424 \pm 35$ & $1,400 \pm 126$ & $759 \pm 53$ & $5.4 \times 10^{5}$ \\
\hline $\mathrm{GlpK}_{\mathrm{Tk}}-$ AceK $_{\mathrm{Ms}}-\mathrm{Est}_{\mathrm{Aa}}$ & $398 \pm 29$ & $1,197 \pm 114$ & $1,084 \pm 27$ & $9.1 \times 10^{5}$ \\
\hline GlpK $_{\text {Tk }}-A_{T P} P_{\text {teth }}-A_{c e} K_{M s}-E s t 2_{\mathrm{Aa}}$ & ND & ND & ND & ND \\
\hline
\end{tabular}

\section{Glycerol-3-phosphate oxidation}

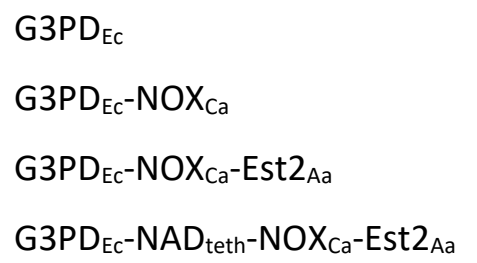

$\begin{array}{lccl}158 \pm 24 & 59 \pm 4 & 85 \pm 11 & 1.4 \times 10^{6} \\ 176 \pm 12 & 369 \pm 17 & 7 \pm 0.7 & 1.8 \times 10^{4} \\ 164 \pm 10 & 659 \pm 47 & 7 \pm 0.6 & 1.1 \times 10^{4} \\ \text { ND } & 659 \pm 47 & 9 \pm 0.6 & 1.4 \times 10^{4}\end{array}$

\section{Oxygen reduction (NADH oxidation)}

$\begin{array}{lllll}\text { Nox }_{\mathrm{Ca}} & 258 \pm 21 & \mathrm{ND} & 1,252 \pm 182 & 4.9 \times 10^{6} \\ \text { G3PD }_{\mathrm{Ec}}-\mathrm{NOX}_{\mathrm{Ca}} & 276 \pm 9 & \mathrm{ND} & 1,714 \pm 252 & 6.2 \times 10^{6} \\ \text { G3PD }_{\mathrm{Ec}}-\mathrm{NOX}_{\mathrm{Ca}}-\mathrm{Est2}_{\mathrm{Aa}} & 266 \pm 15 & \mathrm{ND} & 1,224 \pm 114 & 4.6 \times 10^{6} \\ \text { G3PD }_{\mathrm{Ec}}-\mathrm{NAD}_{\text {teth }}-\mathrm{NOX}_{\mathrm{Ca}}-\mathrm{Est2}_{\mathrm{Aa}} & \mathrm{ND} & \mathrm{ND} & \mathrm{ND} & \mathrm{ND}\end{array}$

\section{Aldol addition}

DHAP

\begin{tabular}{|c|c|c|c|c|}
\hline FruA $_{s c}$ & NA & $500 \pm 80$ & $16 \pm 2$ & $3.2 \times 10^{4}$ \\
\hline FruA $_{s c}-\mathrm{Est} 2_{A a}$ & NA & $70 \pm 11$ & $9 \pm 1$ & $1.3 \times 10^{5}$ \\
\hline
\end{tabular}

\section{Esterase $^{1}$}

\begin{tabular}{|c|c|c|c|c|}
\hline Est2 $2_{\mathrm{Aa}}$ & NA & $180 \pm 40$ & $153 \pm 12$ & $8.3 \times 10^{5}$ \\
\hline $\mathrm{GlpK}_{\mathrm{TK}}-\mathrm{AceK}_{\mathrm{Ms}}-\mathrm{Est}_{2 \mathrm{Aa}}$ & NA & $165 \pm 18$ & $149 \pm 16$ & $8.8 \times 10^{5}$ \\
\hline$G 3 P_{E c}-N O X_{C a}-E s t 2_{A a}$ & NA & $152 \pm 28$ & $159 \pm 11$ & $9.0 \times 10^{5}$ \\
\hline FruA $_{s c}-\mathrm{Est}_{A a}$ & NA & $100 \pm 10$ & $165 \pm 18$ & $1.7 \times 10^{6}$ \\
\hline
\end{tabular}




\section{ON-LINE METHODS}

\section{General}

320 Unless otherwise stated in the text, all chemicals were purchased from Sigma-Aldrich (Merck, 321 Australia). For the flow reactors, regulated flow rates and mixing was provided by a modified Biologic 322 DuoFlow system with a Biologic Fraction Collector (Biorad laboratories Inc., USA) for collection of samples. Biologic DuoFlow software v 5.10 Build 2 (Biorad Laboratories Inc., USA) was used to program and control the system, as per manufacturer's instructions. All restriction enzymes and T4 DNA ligase enzymes used for DNA manipulation were purchased from New England Bioabas (NEB, USA). All PEG compounds were purchased from Quanta BioDesign Ltd (Plain City, OH, USA) and used as received. All other reagents and solvents were obtained from Sigma-Aldrich (Merck), Acros Organics or TCl Chemicals and used as-purchased. Nuclear Magnetic resonance (NMR) spectra were recorded with a Bruker Avance $400 \mathrm{MHz}$ spectrometer in the deuterated solvents as specified. Chemical shifts $(\delta)$ were calibrated against residual solvent peaks and are quoted in ppm relative to TMS. Unless otherwise specified in the text, analytical high-performance liquid chromatography (aHPLC) was performed with a Waters Alliance e2695 Separations Module equipped with Waters 2998 PDA and Acquity QDa detectors, using a Waters XBridge BEH C18 column, $130 \AA$, $3.5 \mu \mathrm{m}, 2.1 \times 50 \mathrm{~mm}$. The following buffer system and gradients were applied: Milli-Q water (Merk Millipore) with $0.1 \%$ formic acid (Buffer A) and $\mathrm{CH}_{3} \mathrm{CN}$ with 0.1\% formic acid (Buffer B), with a gradient of 0-90\% Buffer $\mathrm{B}$ unless otherwise specified.

Semi-preparative reversed-phase high performance liquid chromatography (RP-pHPLC) was undertaken using a Shimadzu SPD-10A UV-Vis detector with UV detection at $\lambda 260 \mathrm{~nm}$. The system was equipped with a Shimadzu 322 pump and Gilson 255 Liquid Handler and set at a flow rate of 10 $\mathrm{mL} \mathrm{min}{ }^{-1}$. Peak separation was achieved using a Vydac $218 T$ T1022 C18, $10 \mu \mathrm{m}, 22$ × $250 \mathrm{~mm}$ column. Solvent gradients used Milli-Q water with 0.1\% TFA (Buffer A) and acetonitrile with 0.1\% TFA (Buffer B), with a gradient of $0-70 \%$ Buffer B unless otherwise specified.

\section{DNA manipulation}

The pAF1 vector that encodes the DHAP-dependent fructose-1,6-biphosphate aldolase from Staphylococcus carnosus was a gift from Dr A. Frazer (University of Manchester, Manchester, UK). For all other constructs, the gene of interest was sourced as described previously ${ }^{25}$, codon-optimized for 
pETCC2 ${ }^{26}$ (a modified version of pET14b, Novagen) using Nde I and Bam HI or Eco RI sites, to create an in-frame $\mathrm{N}$-terminal hexa-histidine tag. Genes encoding fusions between the catalytic and cofactorrecycling domains $\left(G \mid p K_{T K}-A_{c e} K_{M S}\right.$ and $\left.G 3 P D_{E c}-N_{O X} X_{C a}\right)$ were synthesized. Two versions of the synthetic genes were made. In the first version, a single open reading frame containing both domains, separated by a linker and terminating in a STOP codon were synthesized, and included a 5' Nde I site and 3' Bam HI site for cloning. The second version differed in that the stop codon was omitted and a 3' Sph 1 site was included to allow construction of the fusions that included the conjugation domain. The versions with a STOP codon were cloned into pETCC2 for expression and purification of $\mathrm{GlpK}_{\mathrm{Tk}}-\mathrm{AceK}_{\mathrm{MS}}$ and G3PDEc $-N_{C X}$, whilst the Nde I-Sph I versions were subcloned into a prepared pETCC2 backbone containing the esterase $e 2_{\mathrm{Aa}}$ gene to create a genetic fusion via the Sph I site, with a short Gly-Ser

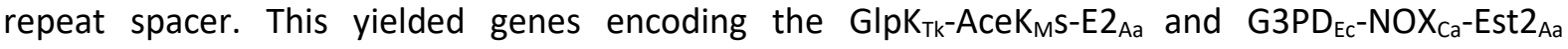
nanomachines. A similar strategy was used to fuse fruA $\mathrm{Asc}_{\mathrm{c}}$ with $e 2_{\mathrm{Aa}}$ via the $S p h$ I site yielding a construct encoding FruAsc-Est2 $2_{\mathrm{Aa}}$ (Supplementary Figure 1). The final insertion fragments used for each of the nanomachines are depicted in Supplementary Figure 1. All constructs were confirmed by DNA sequencing (Macrogen, S. Korea). 
a

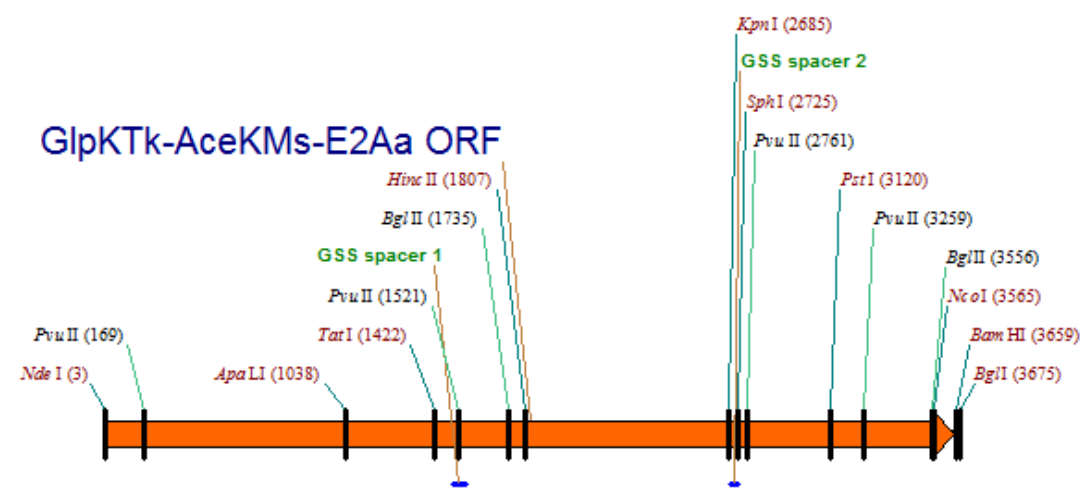

$3678 \mathrm{bp}$

b

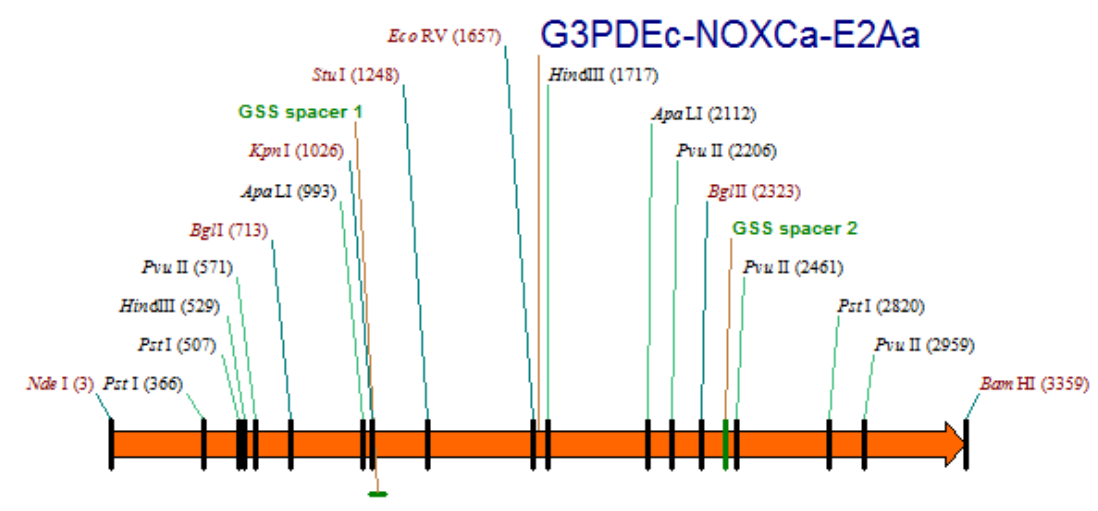

$3363 \mathrm{bp}$

C

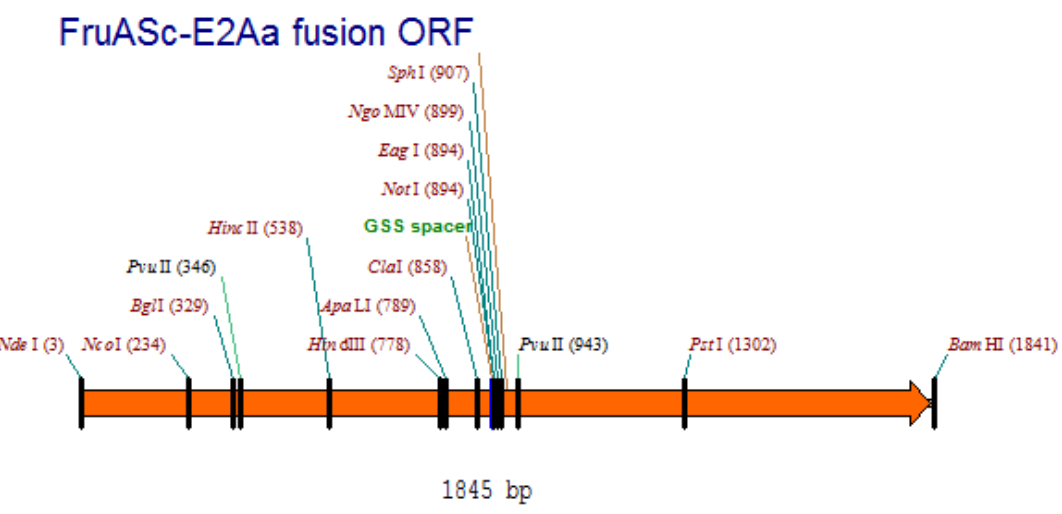

Supplementary Figure 1. DNA insertion regions for each of the nanomachine expression constructs encoding $\mathrm{GlpK}_{\mathrm{TK}}-\mathrm{AceK}_{\mathrm{MS}}-\mathrm{E} 2_{\mathrm{Aa}}(\mathrm{a}), \mathrm{G} \mathrm{PD}_{\mathrm{Ec}}-\mathrm{NOX}_{\mathrm{Ca}}-\mathrm{Est2}_{\mathrm{Aa}}$ (b) and FruAsc$-\mathrm{Est}_{\mathrm{Aa}}$ (c), combining each multienzyme fusion as a single ORF for insertion into pETCC2 via the Nde 1-Bam H1 sites to create an in-frame $5^{\prime}$-hexahistidine tag. 
374 The hexaHIS-tagged individual and fusion protein sequences used in this study are listed below, with

375 linker regions between the protein domains highlighted in bold and underlined, and the cysteine required for tethering modified cofactor highlighted in red bold font:

\section{G3PDEc}

379 MNQRNASMTVIGAGSYGTALAITLARNGHEVVLWGHDPEHIATLERDRCNAAFLPDVPFPDTLHLESD

380 LATALAASRNILVVVPSHVFGEVLRQIKPLMRPDARLVWATKGLEAETGRLLQDVAREALGDQIPLAV ISGPTFAKELAAGLPTAISLASTDQTFADDLQQLLHCGKSFRVYSNPDF IGVQLGGAVKNVIAIGAGM SDGIGFGANARTALITRGLAEMSRLGAALGADPATFMGMAGLGDLVLTCTDNQSRNRRFGMMLGQGMD VQSAQEKIGQVVEGYRNTKEVRELAHRFGVEMPITEEIYQVLYCGKNAREAALTLLGRARKDERSSH*

\section{Nox $_{\mathrm{Ca}}$}

MGSSHHHHHHSSGLVPRGSHMKIVVIGCTHAGTAAVKTILKENPEAEITIFERNDNISFLSCGIALYV GGVVKDPAGLFYSNPEELSKMGANVKIKHNVKS IDTKSKKVIAEDMNTGEEIEVSYDKLVNTTGSWPI

387 IPPIPGIESKNILLCKNYDQANVIIRQTKDAKKIVIVGGGYIGIELVEAFQKSGKQVTLIDGLDRILN 388 KYLDKEFTDILEDDLKKNGINLALDQCVKSFKANENGEVTSVETTKGEYEADMVILCVGFRPNNELLK GKVDMLPNDA I IVDEYMRTSDPDIFAAGDSCAVHYNPNGNYAYI PLATNAVRMGMLIGKNISTPKVKY RGTQSTSGLNLFGYNIGSTGVTVSGAPQIGLNVRSVIVKDNYRPEFMPTNEEI IMQLVYEVGTNRIVG GQVMSKYDITQSANTLSLAIQNKMTIEDLAYVDFFFQPHFDRPWNYLNILGLAALEQEGL*

\section{$\mathrm{GlpK}_{\mathrm{Tk}}$}

MGSSHHHHHHSSGLVPRGSHMEKFVLSLDEGTTSARA I I FDRESNI HG IGQYEFPQHYPRPGWVEHNP EEIWDAQLRAIKDAIQSARIEPNQIAAIGVTNQRETTLVWDKDGKPLYNAIVWQCRRTAEMVEEIKRE YGTMIKEKTGLVPDAYFSASKLKWLLDNVPGLREKAEKGEVMFGTVDTFLIYRLTGEHVTDYSNASRT MLFNIKKLDWDDELLELFDIPESVLPEVRESSEVYGYTKKELLGAEI PVSGDAGDQQAALFGQAAFEA GMVKATYGTGSFILVNTDKMVLYSDNLLTTIAWGLNGRVSYALEGS IFVTGAAVQWLRDGIKI IKHAS ETEELATKLESNEGVYFVPAFVGLGAPYWDQFARGI I IGITRGTGREHLARATLEAIAYLTRDVVDEM EKLVQ IKELRVDGGATANDFLMQFQADI LNRKVIRPVVKETTALGAAYLAGLAVDYWADTREIAELWK AERIFEPKMDEKTRERLYKGWKEAVKRAMGWAKVVDSAKSN*

401

\section{AceK $_{\mathrm{Ms}}$}

402 MGSSHHHHHHSSGLVPRGSHMTVLVVNSGSSSLKYAVVRPASGEFLADGI IEEIGSGAVPDHDAALRA 403 AFDELAAAGLHLEDLDLKAVGHRMVHGGKTFYKPSVVDDELIAKARELSPLAPLHNPPAIKGIEVARK LLPDLPHIAVFDTAFFHDLPAPASTYAIDRELAETWHIKRYGFHGTS HEYVSQQAAIFLDRPLESLNQ IVLHLGNGASASAVAGGKAVDTSMGLTPMEGLVMGTRSGDIDPGVIMYLWRTAGMSVDDIESMLNRRS 


\section{GlpK $_{T k}-A^{-} K_{M} s$}

409

MGSSHHHHHHSSGLVPRGSHMEKFVLSLDEGTTSARA I IFDRESNI HGIGQYEFPQHYPRPGWVEHNP

410 EEIWDAQLRAIKDAIQSARIEPNQIAAIGVTNQRETTLVWDKDGKPLYNAIVWQCRRTAEMVEEIKRE YGTMIKEKTGLVPDAYFSASKLKWLLDNVPGLREKAEKGEVMFGTVDTFLIYRLTGEHVTDYSNASRT

412 MLFNIKKLDWDDELLELFDIPESVLPEVRESSEVYGYTKKELLGAEIPVSGDAGDQQAALFGQAAFEA

413 GMVKATYGTGSFILVNTDKMVLYSDNLLTTIAWGLNGRVSYALEGS IFVTGAAVQWLRDGIKIIKHAS

414 ETEELATKLESNEGVYFVPAFVGLGAPYWDQFARGI I IGITRGTGREHLARATLEAIAYLTRDVVDEM 415 EKLVQIKELRVDGGATANDFLMQFQADILNRKVIRPVVKETTALGAAYLAGLAVDYWADTREIAELWK 416 AERIFEPKMDEKTRERLYKGWKEAVKRAMGWAKVVDSAKSNGSSGSSGSSCGSSGSSGSSMTVLVVNS 417 GSSSLKYAVVRPASGEFLADGI IEEIGSGAVPDHDAALRAAFDELAAAGLHLEDLDLKAVGHRMVHGG 418 KTFYKPSVVDDELIAKARELSPLAPLHNPPAIKGIEVARKLLPDLPHIAVFDTAFFHDLPAPASTYAI 419 DRELAETWHIKRYGFHGTSHEYVSQQAAIFLDRPLESLNQIVLHLGNGASASAVAGGKAVDTSMGLTP 420 MEGLVMGTRSGDIDPGVIMYLWRTAGMSVDDIESMLNRRSGVLGLGGASDFRKLRELIESGDEHAKLA 421 YDVYIHRLRKYIGAYMAVLGRTDVISFTAGVGENVPPVRRDALAGLGGLGIEIDDALNSAKSDEPRLI STPDSRVTVLVVPTNEELAIARACVGVV*

\section{G3PDEc-NOX}

MGSSHHHHHHSSGLVPRGSHMNQRNASMTVIGAGSYGTALAITLARNGHEVVLWGHDPEHIATLERDR CNAAFLPDVPFPDTLHLESDLATALAASRNILVVVPSHVFGEVLRQ I KPLMRPDARLVWATKGLEAET GRLLQDVAREALGDQIPLAVISGPTFAKELAAGLPTAISLASTDQTFADDLQQLLHCGKSFRVYSNPD FIGVQLGGAVKNVIAIGAGMSDGIGFGANARTALITRGLAEMSRLGAALGADPATFMGMAGLGDLVLT CTDNQSRNRRFGMMLGQGMDVQSAQEKIGQVVEGYRNTKEVRELAHRFGVEMP ITEE IYQVLYCGKNA REAALTLLGRARKDERSSHGSSGSSGSSGSSGSSGSSMKIVVIGCTHAGTAAVKT I LKENPEAEITIF ERNDNISFLSCGIALYVGGVVKDPAGLFYSNPEELSKMGANVKIKHNVKSIDTKSKKVIAEDMNTGEE IEVSYDKLVNTTGSWP I I PPIPGIESKN I LLCKNYDQANVI IRQTKDAKKIVIVGGGY I GIELVEAFQ KSGKQVTLIDGLDRILNKYLDKEFTDILEDDLKKNGINLALDQCVKSFKANENGEVTSVETTKGEYEA DMVILCVGFRPNNELLKGKVDMLPNDA I IVDEYMRTSDPDIFAAGDSCAVHYNPNGNYAY I PLATNAV RMGMLIGKNISTPKVKYRGTQSTSGLNLFGYNIGSTGVTVSGAPQIGLNVRSVIVKDNYRPEFMPTNE EI IMQLVYEVGTNRIVGGQVMSKYDITQSANTLSLAIQNKMT IEDLAYVDFFFQPHF DRPWNYLNILG LAALEQEGL *

\section{$437 \quad$ GlpK $_{\text {Tk-AceK }}$ Ms-E2 Aa}

438 MGSSHHHHHHSSGLVPRGSHMEKFVLSLDEGTTSARA I IFDRESNI HGIGQYEFPQHYPRPGWVEHNP 439 EEIWDAQLRAIKDAIQSARIEPNQIAAIGVTNQRETTLVWDKDGKPLYNAIVWQCRRTAEMVEEIKRE 440 YGTMIKEKTGLVPDAYFSASKLKWLLDNVPGLREKAEKGEVMFGTVDTFLIYRLTGEHVTDYSNASRT 441 MLFNIKKLDWDDELLELFDIPESVLPEVRESSEVYGYTKKELLGAEIPVSGDAGDQQAALFGQAAFEA 442 GMVKATYGTGSFILVNTDKMVLYSDNLLTTIAWGLNGRVSYALEGS IFVTGAAVQWLRDGIKI IKHAS 
ETEELATKLESNEGVYFVPAFVGLGAPYWDQFARGI I IGITRGTGREHLARATLEAIAYLTRDVVDEM EKLVQIKELRVDGGATANDFLMQFQADI LNRKVIRPVVKETTALGAAYLAGLAVDYWADTREIAELWK AERIFEPKMDEKTRERLYKGWKEAVKRAMGWAKVVDSAKSNGSSGSSGSSCGSSGSSGSSMTVLVVNS GSSSLKYAVVRPASGEFLADGI IEEIGSGAVPDHDAALRAAFDELAAAGLHLEDLDLKAVGHRMVHGG KTFYKPSVVDDELIAKARELSPLAPLHNPPAIKGIEVARKLLPDLPHIAVFDTAFFHDLPAPASTYAI DRELAETWHIKRYGFHGTSHEYVSQQAA I FLDRPLES LNQ IVLHLGNGASASAVAGGKAVDTSMGLTP MEGLVMGTRSGDIDPGVIMYLWRTAGMSVDDIESMLNRRSGVLGLGGASDFRKLRELIESGDEHAKLA YDVYI HRLRKYIGAYMAVLGRTDVISFTAGVGENVP PVRRDALAGLGGLGIEIDDALNSAKSDEPRLI STPDSRVTVLVVPTNEELAIARACVGVVGTGSSGSSGSSGSSMPLDPVIQQVLDQLNRMPAPDYKHLS AQQFRSQQSLFPPVKKEPVAEVREFDMDLPGRTLKVRMYRPEGVEPPYPALVYYHGGGWVVGDLETHD PVCRVLAKDGRAVVFSVDYRLAPEHKFPAAVEDAYDALQWIAERAADFHLDPARIAVGGDSAGGNLAA VTS ILAKERGGPALAFQLLIYPSTGYDPAHPPAS IEENAEGYLLTGGMMLWFRDQYLNSLEELTHPWF SPVLYPDLSGLPPAYIATAQYDPLRDVGKLYAEALNKAGVKVEIENFEDLIHGFAQFYSLSPGATKAL

\section{G3PD $\mathrm{Ec}_{\mathrm{Ec}}-\mathrm{NOX} \mathrm{Xa}-\mathrm{Est} 2_{\mathrm{Aa}}$}

459 MGSSHHHHHHSSGLVPRGS HMNQRNASMTVIGAGSYGTALAITLARNGHEVVLWGHDPEHIATLERDR CNAAFLPDVPFPDTLHLESDLATALAASRNILVVVPSHVFGEVLRQIKPLMRPDARLVWATKGLEAET GRLLQDVAREALGDQI PLAVISGPTFAKELAAGLPTAISLASTDQTFADDLQQLLHCGKSFRVYSNPD FIGVQLGGAVKNVIAIGAGMSDGIGFGANARTALITRGLAEMSRLGAALGADPATFMGMAGLGDLVLT CTDNQSRNRRFGMMLGQGMDVQSAQEKIGQVVEGYRNTKEVRELAHRFGVEMP ITEE IYQVLYCGKNA REAALTLLGRARKDERSSHGTSGSSGSSCGSSGSSGSSMKIVVIGCTHAGTAAVKT I LKENPEAEITI FERNDNISFLSCGIALYVGGVVKDPAGLFYSNPEELSKMGANVKIKHNVKS I DTKSKKVIAEDMNTGE EIEVSYDKLVNTTGSWPI I PP I PGIESKNI LLCKNYDQANVI IRQTKDAKKIVIVGGGYIGIELVEAF QKSGKQVTLIDGLDRILNKYLDKEFTDILEDDLKKNGINLALDQCVKSFKANENGEVTSVETTKGEYE ADMVILCVGFRPNNELLKGKVDMLPNDA I IVDEYMRTSDPDIFAAGDSCAVHYNPNGNYAYIPLATNA VRMGMLIGKNISTPKVKYRGTQSTSGLNLFGYNIGSTGVTVSGAPQIGLNVRSVIVKDNYRPEFMPTN EEI IMQLVYEVGTNRIVGGQVMSKYDITQSANTLSLAIQNKMTIEDLAYVDFFFQPHFDRPWNYLNIL GLAALEQEGLGSSMPLDPVIQQVLDQLNRMPAPDYKHLSAQQFRSQQSLFP PVKKEPVAEVREFDMDL PGRTLKVRMYRPEGVEPPYPALVYYHGGGWVVGDLETHDPVCRVLAKDGRAVVFSVDYRLAPEHKFPA AVEDAYDALQWIAERAADFHLDPARIAVGGDSAGGNLAAVTS ILAKERGGPALAFQLLIYPSTGYDPA HPPAS IEENAEGYLLTGGMMLWFRDQYLNSLEELTHPWFS PVLYPDLSGLPPAYIATAQYDPLRDVGK LYAEALNKAGVKVEIENFEDLIHGFAQFYSLSPGATKALVRIAEKLRDALA*

\section{FruAsc-Est2 ${ }_{\text {Aa }}$}

478 MGSSHHHHHHSSGLVPRGSHMKILAITSCPNGIAHTYMAQEKLEQAAKEMGVDIKVETQGGVGAENVL 
bioRxiv preprint doi: https://doi.org/10.1101/568972; this version posted March 5, 2019. The copyright holder for this preprint (which was not certified by peer review) is the author/funder, who has granted bioRxiv a license to display the preprint in perpetuity. It is made available under aCC-BY-NC-ND 4.0 International license.

EEEKKSGVQMVYQHLMNGVSFMVPFIVVGGLLIAIALTLGGEPSAKGLVIPDDSFWKS IEKIGALSFS FMVPILAGYIAYSIADKPGLVPGMIGGAIAADGSFYGSEAGAGFLGGIVAGFLAGYIAKWIKNVKVPK AMAP IMP I I I P I ISSVIVGLIFIFLIGAP ISG IFTALTGWLKGMQGAN IVVLALI I GAMIAF DMGGP VNKVAFLFGSALIAEGNYAVMGMVAVAVCTPP IGLGLATFLQKGKFNNSEQEMGKASFTMGLFGITEG AIPFAAQDPLRI IPANMIGAMVAAVIAALGGVGDRVAHGGP IVAVLGGIQHVLWFFVAVI IGSLITMF TVLLFKKNTPVAVLEGEGVVEDGIGDGQSHSNNQVAESRTENNEQKDDDSVFHKDLIELRQESMQRDN AIDQLLEKLKDAGYIESLDKVKEAVLQREAESTTAIGMNVAIPHAKSDAVKQPAVAVLQDKQGIEWES LDGTSPKIVFLIVVPNNSNDTHLKLLQRLSRALMDDETRENLINATTKDEIYNILKMIGSMPLDPVIQ QVLDQLNRMPAPDYKHLSAQQFRSQQSLFPPVKKEPVAEVREFDMDLPGRTLKVRMYRPEGVEPPYPA LVYYHGGGWVVGDLETHDPVCRVLAKDGRAVVFSVDYRLAPEHKFPAAVEDAYDALQWIAERAADFHL DPARIAVGGDSAGGNLAAVTS ILAKERGGPALAFQLLIYPSTGYDPAHPPAS IEENAEGYLLTGGMML WFRDQYLNSLEELTHPWFS PVLYPDLSGLPPAYIATAQYDPLRDVGKLYAEALNKAGVKVEIENFEDL IHGFAQFYSLSPGATKALVRIAEKLRDALA*

\section{Protein Expression and Purification}

\section{Expression of individual enzymes and bi-enzymatic fusion proteins.}

The expression plasmids outlined above were used to transform E. coli BL21 DE3 Star (Invitrogen, ThermoFisher Scientific, USA), using Luria agar containing $100 \mu \mathrm{g} \mathrm{mL}^{-1}$ ampicillin as a selective growth medium. Cells were cultured overnight in Luria broth containing $100 \mu \mathrm{g} \mathrm{mL}^{-1}$ ampicillin at $37^{\circ} \mathrm{C}$ and shaken at $200 \mathrm{rpm}$, then induced for 2, 4, 6 and $24 \mathrm{~h}$ with either arabinose or isopropyl $\beta$-D-1thiogalactopyranoside (IPTG) at $0.2 \mathrm{M}$ and $1 \mathrm{mM}$ final concentration, respectively (see Supplementary Table 1 for details). Cultures were then harvested, by centrifugation at $8000 \mathrm{~g}$, resuspended in one tenth culture volume of resuspension buffer (50 mM Tris-Cl, $250 \mathrm{mM} \mathrm{NaCl}, \mathrm{pH} 7.5)$ and lyzed with Bugbuster $^{\mathrm{TM}}$ (Novagen). Protein expression was analyzed by SDS-PAGE separation (4-12\% Bolt Bis-Tris Plus Polyacrylamide Gel with MES SDS running buffer (Invitrogen, USA) and visualized with NuBlue (Novagen). The optimal expression time (Supplementary Table 1) was selected and large scale expression cultures of 1-2 L prepared in the same way as above except that cells were lysed by passage through an EmulsiFlex-C5 cell homogenizer (Avestin) at $20,000 \mathrm{psi}, 4^{\circ} \mathrm{C}$ and cellular debris removed by centrifugation $\left(40,000 \times \mathrm{g}, 15 \mathrm{~min}, 4^{\circ} \mathrm{C}\right)$. Protein was first purified from cell free lysates by IMAC purification of HIS-tagged protein by elution with resuspension buffer $(50 \mathrm{mM}$ Tris-Cl, $250 \mathrm{mM} \mathrm{NaCl}$, $\mathrm{pH}$ 7.5) containing increasing concentration of imidazole from NiNTA-sepharose (Hi5 HIS-TRAP, GE Healthcare). The desired protein fractions were then pooled and further purified using a Superdex 200 size exclusion column (GE Healthcare). Pooled fractions were then concentrated and stored at $4{ }^{\circ} \mathrm{C}$, or $-80^{\circ} \mathrm{C}$, as required. 
516 Supplementary Table 1. Optimal recombinant expression conditions for the individual enzymes and 517 multi-enzyme fusions comprising each nanomachine.

\begin{tabular}{|c|c|c|c|c|}
\hline Enzyme & Construct & $\begin{array}{l}\text { Expression } \\
\text { Vector }\end{array}$ & Host Cells & $\begin{array}{ll}\text { Inducer; } & \text { Induction } \\
\text { Temperature } & \left({ }^{\circ} \mathrm{C}\right) \text { and } \\
\text { Time }[\mathrm{h}] & \end{array}$ \\
\hline \multicolumn{5}{|c|}{ Phosphotransfer Nanomachine Proteins } \\
\hline $\mathrm{GlpK}_{T K}$ & $\mathrm{pCJH} 1$ & pETCC2 & $\begin{array}{l}\text { E.coli BL21DE3 Star } \\
\text { (Invitrogen) }\end{array}$ & $\begin{array}{l}1 \mathrm{mM} \text { IPTG; } \\
37^{\circ} \mathrm{C}, 18 \mathrm{~h}\end{array}$ \\
\hline AceK $_{\mathrm{Ms}}$ & $\mathrm{pCJH} 2$ & $\begin{array}{l}\text { pDEST17 } \\
\text { (Invitrogen) }\end{array}$ & $\begin{array}{l}\text { E.coli BL21Al } \\
\text { (Invitrogen) }\end{array}$ & $\begin{array}{l}20 \mathrm{mM} \text { arabinose } \\
15^{\circ} \mathrm{C}, 18 \mathrm{~h}\end{array}$ \\
\hline $\mathrm{GlpK}_{\mathrm{TK}}-\mathrm{AceK}_{\mathrm{Ms}}$ & $\mathrm{pCJH} 3$ & pETCC2 & $\begin{array}{l}\text { E.coli BL21DE3 Star } \\
\text { (Invitrogen) }\end{array}$ & $\begin{array}{l}1 \mathrm{mM} \text { IPTG; } \\
37^{\circ} \mathrm{C}, 18 \mathrm{~h}\end{array}$ \\
\hline $\mathrm{GlpK}_{\mathrm{TK}}-\mathrm{AceK}_{\mathrm{Ms}}-\mathrm{Est2}_{\mathrm{Aa}}$ & $\mathrm{pCJH} 4$ & pETCC2 & $\begin{array}{l}\text { E.coli BL21DE3 Star } \\
\text { (Invitrogen) }\end{array}$ & $\begin{array}{l}1 \mathrm{mM} \text { IPTG; } \\
37^{\circ} \mathrm{C}, 18 \mathrm{~h}\end{array}$ \\
\hline \multicolumn{5}{|c|}{ Oxidation Nanomachine Proteins } \\
\hline $\mathrm{G} \mathrm{PD}_{\mathrm{EC}}$ & pCJH5 & $\begin{array}{l}\text { pDEST17 } \\
\text { (Invitrogen) }\end{array}$ & $\begin{array}{c}\text { E.coli BL21AI } \\
\text { (Invitrogen) }\end{array}$ & $\begin{array}{l}20 \mathrm{mM} \text { arabinose } \\
25^{\circ} \mathrm{C}, 18 \mathrm{~h}\end{array}$ \\
\hline NOX $_{\mathrm{Ca}}$ & $\mathrm{pCJH6}$ & pETCC2 & $\begin{array}{l}\text { E.coli BL21DE3 Star } \\
\text { (Invitrogen) }\end{array}$ & $\begin{array}{l}1 \mathrm{mM} \text { IPTG; } \\
37^{\circ} \mathrm{C}, 18 \mathrm{~h}\end{array}$ \\
\hline $\mathrm{G} P \mathrm{D}_{\mathrm{Ec}}-\mathrm{NOX}_{\mathrm{Ca}}$ & $\mathrm{pCJH7}$ & pETCC2 & $\begin{array}{l}\text { E.coli BL21DE3 Star } \\
\text { (Invitrogen) }\end{array}$ & $\begin{array}{l}1 \mathrm{mM} \text { IPTG; } \\
25^{\circ} \mathrm{C}, 18 \mathrm{~h}\end{array}$ \\
\hline $\mathrm{G} P \mathrm{D}_{\mathrm{EC}}-\mathrm{NOX} \mathrm{Ca}_{\mathrm{a}}-\mathrm{Est}_{\mathrm{Aa}}$ & $\mathrm{pCJH8}$ & pETCC2 & $\begin{array}{l}\text { E.coli BL21DE3 Star } \\
\text { (Invitrogen) }\end{array}$ & $\begin{array}{l}1 \mathrm{mM} \text { IPTG; } \\
25^{\circ} \mathrm{C}, 18 \mathrm{~h}\end{array}$ \\
\hline \multicolumn{5}{|c|}{ Aldol addition Nanomachine Proteins } \\
\hline FruA $_{s c}$ & pAF1 & $\begin{array}{l}\text { pRSET-A } \\
\text { (Invitrogen) }\end{array}$ & E.coli BL21DE3 & $\begin{array}{l}1 \mathrm{mM} \text { IPTG; } \\
15^{\circ} \mathrm{C}, 18 \mathrm{~h}\end{array}$ \\
\hline FruAsc-Est2 $2_{\mathrm{Aa}}$ & pCJH9 & pETCC2 & $\begin{array}{l}\text { E.coli BL21DE3 Star } \\
\text { (Invitrogen) }\end{array}$ & $\begin{array}{l}1 \mathrm{mM} \text { IPTG; } \\
15^{\circ} \mathrm{C}, 18 \mathrm{~h}\end{array}$ \\
\hline \multicolumn{5}{|c|}{ Esterase Conjugation Domain Protein } \\
\hline Est2 ${ }_{\mathrm{Aa}}$ & $\mathrm{pCJH} 10$ & pETCC2 & $\begin{array}{l}\text { E.coli BL21DE3 Star } \\
\text { (Invitrogen) }\end{array}$ & $\begin{array}{l}1 \mathrm{mM} \text { IPTG; } \\
37^{\circ} \mathrm{C}, 18 \mathrm{~h}\end{array}$ \\
\hline
\end{tabular}

519 Each of the purified individual and bi-enzymatic fusion proteins were then characterised in terms of 520 catalytic activity (Table 1), thermostability and oligomeric structure (Supplementary Table 2 ) to ensure 521 suitability for incorporation into the final nanomachine constructs with the esterase conjugation 522 domain, utilising the enzymatic activity assays and analytical methods outlined below. Further specific 523 details regarding the expression and purification of the final three nanomachine multi-enzyme fusion proteins used to construct the nanofactory is given below. 


\begin{tabular}{|c|c|c|c|}
\hline Optimal & $T_{50}{ }^{*}$ & Oligomeric Structure & $\boldsymbol{k}_{\mathrm{cat}} / K_{\mathrm{M}}$ \\
\hline $\begin{array}{l}\text { Reaction pH } \\
\text { (pH range) }\end{array}$ & $\left({ }^{\circ} \mathrm{C}\right)$ & & $\left(s^{-1} M^{-1}\right)$ \\
\hline
\end{tabular}

\section{Glycerol phosphorylation}

$\begin{array}{llllll}\text { GlpK }_{T K} & 8.0(6.5-9.5) & >100 & \text { monomer } & 6.1 \times 10^{7} & 27 \text {; This study } \\ \text { GlpK }_{\text {TK}}-\text { AceK }_{\mathrm{Ms}} & & 58 & \text { dimer } & 7.7 \times 10^{7} & \text { This study } \\ \text { GlpK }_{\text {TK }}-\text { AceK }_{\mathrm{Ms}}-\text { Est2 }_{\mathrm{Aa}} & & 59 & \text { monomer/hexamer } & 8.6 \times 10^{7} & \text { This study }\end{array}$

Acetate dephosphorylation (ADP phosphorylation)

$\begin{array}{llllll}\text { AceK }_{\mathrm{Ms}} & 7.4(6.0-8.5) & 52 & \text { homodimer } & 2.8 \times 10^{6} & \text { 28; This study } \\ \text { GlpK }_{\text {Tk }}-\text { AceK }_{\mathrm{Ms}} & & 50 & \text { dimer } & 5.4 \times 10^{5} & \text { This study } \\ \text { GlpK }_{\text {Tk }}-\text { AceK }_{\mathrm{Ms}}-\mathrm{Esst}_{\mathrm{Aa}} & & 63 & \text { monomer/hexamer } & 9.1 \times 10^{5} & \text { This study }\end{array}$

\section{Glycerol-3-phosphate oxidation}

\begin{tabular}{|c|c|c|c|c|c|}
\hline $\mathrm{G} P \mathrm{PD}_{\mathrm{Ec}}$ & $9.0(8.0-9.5)$ & 51 & monomer & $1.4 \times 10^{6}$ & 18; This study \\
\hline $\mathrm{G} \mathrm{PD}_{\mathrm{Ec}}-\mathrm{NOX}_{\mathrm{Ca}}$ & & 37 & dimer & $1.8 \times 10^{4}$ & This study \\
\hline G3PD $D_{E c}-N O X_{C a}-E s t 2_{A a}$ & & 45 & dimer & $1.1 \times 10^{4}$ & This study \\
\hline
\end{tabular}

\section{Oxygen reduction (NADH oxidation)}

\begin{tabular}{|c|c|c|c|c|c|}
\hline Nox $_{\mathrm{Ca}}$ & $7.0(7.0-9.0)$ & 37 & homodimer & $4.9 \times 10^{6}$ & 29; This study \\
\hline $\mathrm{G} \mathrm{PD}_{\mathrm{Ec}}-\mathrm{NOX}_{\mathrm{Ca}}$ & & 37 & dimer & $6.2 \times 10^{6}$ & This study \\
\hline G3PD $D_{E c}-N O X_{C a}-E s t 2_{A a}$ & & 37 & dimer & $4.6 \times 10^{6}$ & This study \\
\hline
\end{tabular}

\section{Aldol addition}

$\begin{array}{llllll}\text { FruA } & >95 & \text { monomer } & 3.2 \times 10^{4} & 30 \\ \text { FruA }_{s c} \text {-Est2 }_{A a} & 6.5-9.0 & 81 & \text { monomer } & 1.3 \times 10^{5} & \text { This study } \\ \text { sterase }^{1} & & & & & \\ \text { Est2 }_{\mathrm{Aa}} & 7.1(5.5-8.0) & 80 & \text { monomer } & 8.3 \times 10^{5} & \text { 31; This study }\end{array}$

$528 * T_{50}$ the temperature at which, after $30 \mathrm{~min}$ of incubation, $50 \%$ of the initial enzyme activity remains. The $T_{50}$ 529 values are the averages of at least three independent assays. Standard deviations were below $1.0{ }^{\circ} \mathrm{C}$ in all cases. $530 \mathrm{pH}$ optima did not vary between individual and fusion enzymes.

\section{Expression of $\mathrm{GlpK}_{\mathrm{Tk}}-\mathrm{AceK}_{\mathrm{Ms}}-\mathrm{E} \mathbf{2}_{\mathrm{Aa}}$.}

533 The expression of $\mathrm{GlpK}_{T K^{-}}-\mathrm{AceK}_{M S} \mathrm{~S}-\mathrm{E} 2_{A a}$ in E. coli BL21 DE3 Star (Invitrogen, ThermoFisher Scientific, USA)

534 cells transformed with the plasmid pETCC2- GlpK ${ }_{T k}-$ AceK $_{M S}-E 2_{A a}(p C J H 4$; Supplementary Table 1) was

535 examined after induction at $15^{\circ} \mathrm{C}$ for $18 \mathrm{~h}$ with $1 \mathrm{mM} \mathrm{IPTG}$ as inducer, and the oligomeric state related 536 to fusion protein activity, using glycerol kinase activity as a proxy for all three activities (Supplementary 537 Figure 2). Although all three oligomeric states isolated by gel filtration purification (Superdex 150 gel 538 filtration column, GE Healthcare, after pooling HIS-tagged purification pools from a $5 \mathrm{~mL}$ HisTrap FF 
column, GE Healthcare) demonstrated glycerol kinase activity, the maximum specific activity per milligram of protein was retained in the "monomeric-dimeric" fraction (Supplementary Figure 2). For subsequent experiments, the monomeric-dimeric fraction was isolated.

For large scale preparation of $\mathrm{GlpK}_{T K}-\mathrm{AceK}_{M S} \mathrm{~S}-\mathrm{E} 2_{A a}$ fusion protein $\mathrm{pCH} 4$ was transformed into $E$. coli BL21DE3 Star cells. Cells were cultured in Luria broth overnight at $37^{\circ} \mathrm{C}$ with shaking at $200 \mathrm{rpm}$, diluted to $\mathrm{OD}_{600 \mathrm{~nm}} 0.7$ in Luria broth and induced at $15^{\circ} \mathrm{C}$ for $18 \mathrm{~h}$ with arabinose and IPTG $(20 \mathrm{mM}$ and $1 \mathrm{mM}$ final concentration, respectively) and then harvested, washed in one tenth volume resuspension buffer $(50 \mathrm{mM}$ Tris- $\mathrm{Cl}, 250 \mathrm{mM} \mathrm{NaCl}, \mathrm{pH} 7.5)$ and cell pellets stored at $-20^{\circ} \mathrm{C}$. Cell paste (8 g) was resuspended in $200 \mathrm{~mL} 50 \mathrm{mM}$ Tris, $300 \mathrm{mM} \mathrm{NaCl} \mathrm{pH} 8$ containing $0.5 \mathrm{mg} \mathrm{mL}^{-1}$ lysozyme (Sigma-Aldrich), 2 mM PMSF (Sigma-Aldrich), four EDTA-Free Complete Protease inhibitor tablets (Roche) and 1000 Units Benzonase (Merck Millipore). Following resuspension, the cells were ruptured by passage three times through an EmulsiFlex-C5 cell homogenizer (Avestin) at 15,000 psi at $4^{\circ} \mathrm{C}$ and cellular debris removed by centrifugation $\left(40,000 \times \mathrm{g}, 15 \mathrm{~min}, 4^{\circ} \mathrm{C}\right)$. The lysate was filtered $(0.45 \mu \mathrm{m})$ and one quarter applied to a $5 \mathrm{~mL}$ HisTrap FF column (GE Healthcare) equilibrated in $50 \mathrm{mM}$ Tris, 300 $\mathrm{mM} \mathrm{NaCl}$ pH 8 containing $0.1 \mathrm{mM}$ tris-(2-carboxyethyl)phosphine (TCEP). The column was washed with $40 \mathrm{mM}$ imidazole in the same buffer then the bound protein eluted with $300 \mathrm{mM}$ imidazole in the same buffer. The eluted protein was analyzed by gel filtration on a Superdex 2001030 gel filtration column (GE Healthcare) equilibrated with phosphate buffered saline with the absorbance of the eluted protein monitored at $280 \mathrm{~nm}$ and the esterase activity in the eluted fractions determined. For comparison, $0.5 \mathrm{~mL}$ of crude lysate was also subjected to gel filtration analysis, with monitoring at 280 $\mathrm{nm}$ and analysis of esterase activity in the fractions.

\section{Expression and purification of G3PD $\mathrm{Ec}_{\mathrm{E}}-\mathrm{NOX} \mathrm{X}_{\mathrm{Ca}}-\mathrm{Est}_{\mathrm{Aa}}$.}

Briefly, E.coli BL21 DE3 Star (Invitrogen) cells expressing G3PD $\mathrm{Ec}_{\mathrm{C}}-\mathrm{NOX}_{\mathrm{Ca}}-\mathrm{Est2}_{\mathrm{Aa}}(\mathrm{pCJH}$, Supplementary Table 1) were cultured in an XRS 20 bioreactor (Pall Corporation, USA) using a 2 litre volume of M9 minimal medium, with $1 \%(\mathrm{w} / \mathrm{v})$ ammonium sulphate and $1 \%(\mathrm{w} / \mathrm{v})$ glucose as nitrogen and carbon source respectively and supplemented with $100 \mathrm{gg} \mathrm{mL}^{-1}$ ampicillin. After initial growth at $37^{\circ} \mathrm{C}$, the temperature was reduced to $25{ }^{\circ} \mathrm{C}$ prior to induction, when the $\mathrm{OD}_{600 \mathrm{~nm}}$ reached 2.2. The optical density of the culture at induction was $\mathrm{OD}_{600 \mathrm{~nm}} 2.9$ and $1.6 \mathrm{~mL}$ of $20 \%$ arabinose and IPTG to $1 \mathrm{mM}$ were added to induce. The glucose feed was started $7 \mathrm{~h}$ post-induction to maintain $1 \%$ glucose and cells were harvested $22 \mathrm{~h}$ post-induction, when $\mathrm{OD}_{600 \mathrm{~nm}}$ was 21.6 . 
573 Cell paste (2 g) was resuspended in $50 \mathrm{~mL} 50 \mathrm{mM}$ Tris, $300 \mathrm{mM} \mathrm{NaCl} \mathrm{pH} 8$ containing $0.1 \mathrm{mM}$ Tris-(2574 carboxyethyl)phosphine (TCEP; Sigma-Aldrich), $0.5 \mathrm{mg} \mathrm{mL}^{-1}$ lysozyme (Sigma-Aldrich), $2 \mathrm{mM}$ 575 phenylmethane sulfonyl fluoride (PMSF; Sigma-Aldrich), one EDTA-Free Complete Protease inhibitor 576 tablet (Roche) and 250 Units Benzonase (Merck Millipore). Following resuspension, the cells were 577 ruptured by passage three times through an EmulsiFlex-C5 cell homogenizer (Avestin) at 15,000 psi at $5784{ }^{\circ} \mathrm{C}$ and cellular debris removed by centrifugation $\left(40,000 \times \mathrm{g}, 15 \mathrm{~min}, 4^{\circ} \mathrm{C}\right)$. The lysate was filtered $579(0.45 \mu \mathrm{m})$ and applied to a $5 \mathrm{~mL}$ HisTrap FF column (GE Healthcare) equilibrated in $50 \mathrm{mM}$ Tris, 300 $580 \mathrm{mM} \mathrm{NaCl} \mathrm{pH} 8$ containing $0.1 \mathrm{mM}$ TCEP. The column was washed with $40 \mathrm{mM}$ imidazole in the same 581 buffer then the bound protein eluted with $300 \mathrm{mM}$ imidazole in the same buffer. The eluted protein 582 was subjected to gel filtration on a Superdex 200 gel filtration column (GE Healthcare) equilibrated 583 with $50 \mathrm{mM}$ citrate, $200 \mathrm{mM} \mathrm{NaCl} \mathrm{pH} 6$ containing $1 \mathrm{mM}$ TCEP with the absorbance of the eluted 584 protein monitored at 280 and $450 \mathrm{~nm}$. Fractions eluting from $158-192 \mathrm{~mL}$ were pooled and concentrated to $0.94 \mathrm{mg} \mathrm{mL}^{-1}$.

$G 3 P D_{E c}-N O X_{C a}-E s t 2_{A a}$ eluted in a broad peak from the gel filtration column, with some protein eluting in the void volume (Supplementary Figure 2). The final pool was $>95 \%$ pure as estimated by SDS-PAGE and was found to have specific activities of $16 \mathrm{U} \mathrm{mg}^{-1}$ for esterase and $31 \mathrm{U} \mathrm{mg}^{-1}$ for NADH oxidase.

\section{Expression and purification of FruAsc-Est2 ${ }_{\text {Aa. }}$}

591 FruA $_{s c}$ was selected as the preferred aldolase for the nanofactory based on its enantioselectivity (3S, $5924 R$-ADHOP), oligomeric structure, stability, catalytic rate (Supplementary Table 2) and previous 593 success using this enzyme in multi-enzyme cascades to produce similar chiral sugars ${ }^{18}$.

594 For the preparation of the aldol addition nanomachine, we constructed genetic fusions between Frusc and E2 $2_{\mathrm{Aa}}$ as illustrated in Supplementary Figure 1. Purified Frusc $-E 2_{\mathrm{Aa}}$ was obtained by expression and purification from E. coli BL21 DE3 Star cells (Invitrogen, Thermofisher Scientific). Briefly, a synthetic gene encoding FruAsc $-2_{A a}$ was transferred into pETCC2 ( $\mathrm{pCJH10}$, Supplementary Table 1$)$ and used to transform E.coli BL21DE3 Star (Invitrogen) cells. Cells were cultured in Luria broth overnight at $37^{\circ} \mathrm{C}$ with shaking at $200 \mathrm{rpm}$, diluted to $\mathrm{OD}_{600 \mathrm{~nm}} 0.7$ in Luria broth and induced for $18 \mathrm{~h}$ with arabinose and IPTG (20 mM and $1 \mathrm{mM}$ final concentration, respectively). The cells were then harvested, washed in one tenth volume resuspension buffer ( $50 \mathrm{mM}$ Tris- $\mathrm{Cl}, 250 \mathrm{mM} \mathrm{NaCl}, \mathrm{pH} 7.5)$ and cell pellets stored at $-20^{\circ} \mathrm{C}$. Cell paste $(8 \mathrm{~g})$ was resuspended in $200 \mathrm{~mL} 50 \mathrm{mM}$ Tris, $300 \mathrm{mM} \mathrm{NaCl} \mathrm{pH} 8$ containing, $0.5 \mathrm{mg}$ $\mathrm{mL}^{-1}$ lysozyme (Sigma-Aldrich), 2 mM PMSF (Sigma-Aldrich), four EDTA-Free Complete Protease Inhibitor tablets (Roche) and 1000 Units Benzonase (Merck Millipore). Following resuspension, the cells were ruptured by passage three times through an EmulsiFlex-C5 cell homogenizer (Avestin) at 
bioRxiv preprint doi: https://doi.org/10.1101/568972; this version posted March 5, 2019. The copyright holder for this preprint (which was not certified by peer review) is the author/funder, who has granted bioRxiv a license to display the preprint in perpetuity. It is made available under aCC-BY-NC-ND 4.0 International license.

607

608

609

610

611

612

613

614

615

616

617

618

619

620

621

622

623

624

625

626

627

628

629

630

631

632

was filtered $(0.45 \mu \mathrm{m}$ ) and applied to a $5 \mathrm{~mL}$ HisTrap FF column (GE Healthcare) equilibrated in $50 \mathrm{mM}$ Tris, $300 \mathrm{mM} \mathrm{NaCl} \mathrm{pH} 8$ containing $0.1 \mathrm{mM}$ TCEP. The column was washed with $40 \mathrm{mM}$ imidazole in the same buffer then the bound protein eluted with $300 \mathrm{mM}$ imidazole in the same buffer. The eluted protein was analyzed by gel filtration on a Superdex 200/1030 gel filtration column (GE Healthcare) equilibrated with phosphate buffered saline with the absorbance of the eluted protein monitored at $280 \mathrm{~nm}$ (Supplementary Figure 2) and the esterase activity in the eluted fractions determined.

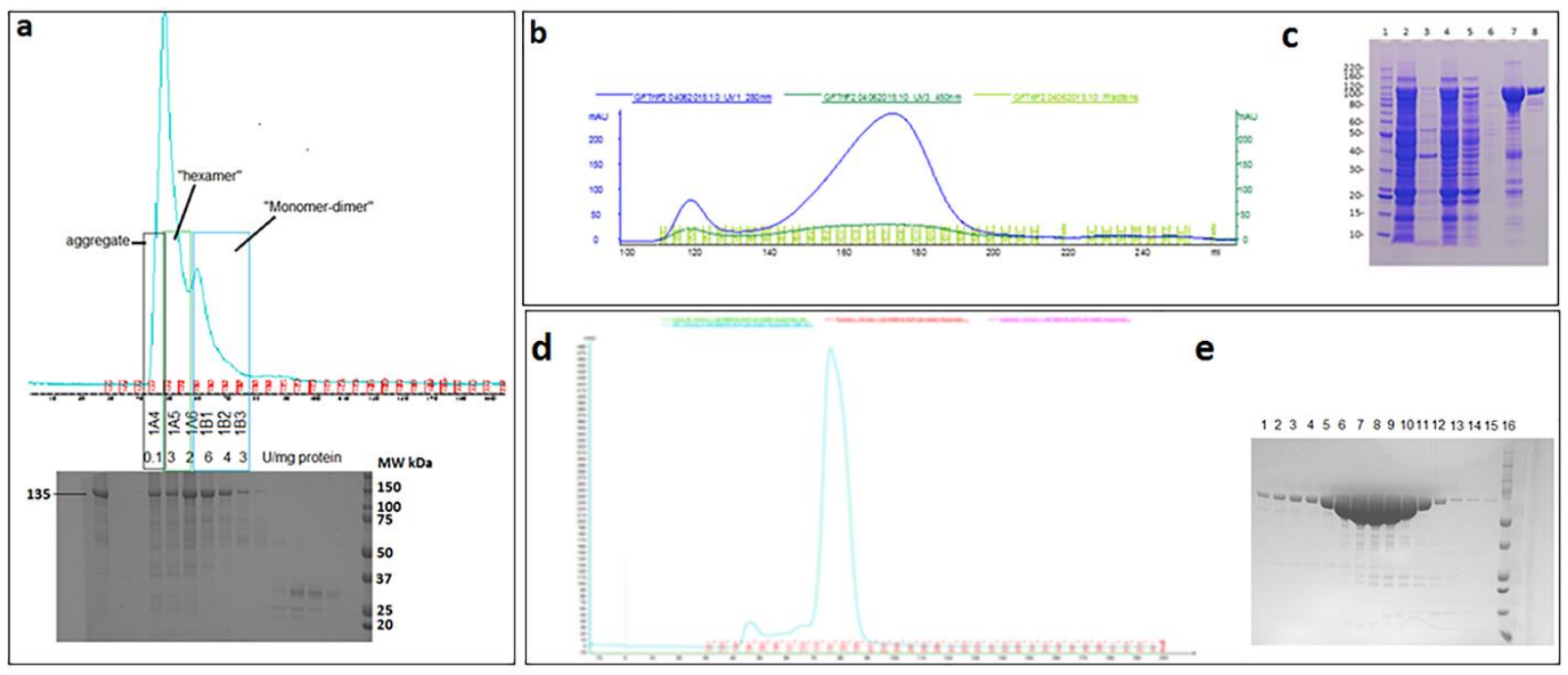

Supplementary Figure 2. Expression and purification of nanomachine fusion proteins. a, Size exclusion fractionation of HIS-tag purified recombinant $\mathrm{GlpK}_{\mathrm{TK}}-\mathrm{AceK}_{\mathrm{Ms}}-\mathrm{E} 2_{\mathrm{Aa}}$ multi-enzyme fusion protein was used to estimate oligomeric state and associated specific activity after induction with $1 \mathrm{mM}$ IPTG at $15{ }^{\circ} \mathrm{C}$ for $24 \mathrm{~h}$. b, Size exclusion fractionation of HIS-tag purified recombinant G3PD $\mathrm{Ec}^{-}$ NOX $_{\text {Ca }}$-Est2 $2_{\text {Aa. }}$. Fractions from $158-192 \mathrm{~mL}$ were pooled to avoid higher MW aggregate. c, SDS-PAGE

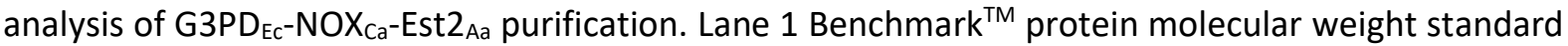
standard (Invitrogen), Lane 2 whole cells, Lane 3 pellet after centrifugation of lysate, Lane 4 lysate, Lane 5 HisTrap unbound, Lane $640 \mathrm{mM}$ imidazole wash, Lane $7300 \mathrm{mM}$ imidazole elution, Lane 8 gel filtration pool. d, Size exclusion fractionation profile of HIS-tag purified recombinant FruAsc-Est $2_{\text {Aa. }}$ e, SDS-PAGE analysis of FruA $\mathrm{Ac}_{\mathrm{c}}-\mathrm{Est}_{\mathrm{Aa}}$ purification. Lane 1 Fraction 1B1, Lanes 2-15 fractions $1 \mathrm{C} 1$ to $2 \mathrm{~A} 3$, Lane 16 Dual $^{\mathrm{TM}}$ Protein molecular weight standard (NEB).

\section{Cofactor modification}

\section{Synthesis of $N^{6}-2 A E-A D P$.}

Adenosine-5'-phosphate sodium salt, ADP.xNa, $(0.5 \mathrm{~g}, 1.13 \mathrm{mmol})$ was dissolved in distilled deionised (DI) water $(1.5 \mathrm{~mL})$ and ethyleneimine $(160 \mu \mathrm{L})$ was added very slowly. During the addition of the ethyleneimine, the $\mathrm{pH}$ was carefully adjusted with perchloric acid to keep it within the $\mathrm{pH}$ range of 
2.0-4.0. The $\mathrm{pH}$ at the end was left at 3.2. The reaction was stirred at room temperature for $\sim 50 \mathrm{~h}$. The solvent was then evaporated in a fume-hood under a stream of nitrogen. The crude residue was dissolved in $\mathrm{DI}$ water $(10 \mathrm{~mL})$ and the $\mathrm{pH}$ adjusted to 5.6 by the addition of lithium hydroxide ( $\mathrm{LiOH}$; saturated aq. solution) and heated at $35{ }^{\circ} \mathrm{C}$ for $80 \mathrm{~h}$. The solution was lyophilized to yield crude $N^{6}-$ 2AE-ADP (Supplementary Scheme 1).

\section{Synthesis of MAL-PEG $24-2 A E-A D P$.}

Crude $N^{6}$-2AE-ADP DIPEA salt (100 mg, crude estimate equivalent to about $13.7 \mathrm{mmol}$ pure 2AE-ADP) was dissolved in $50 \%$ acetonitrile/phosphate buffered saline $\mathrm{pH} 7.0(3.0 \mathrm{~mL})$ and a solution of MAL$\mathrm{PEG}_{24}$-NHS $(43.0 \mathrm{mg}$ ) was added and stirred at room temperature overnight (Supplementary Scheme 1). The mixture was purified by pHPLC and lyophilised to yield pure MAL-PEG ${ }_{24}-2 A E-A D P(12.2 \mathrm{mg})$.

\section{Synthesis of $N^{6}-2 A E-N A D^{+}$.}

To a solution of $\beta$-nicotinamide adenine dinucleotide hydrate, $\mathrm{NAD}^{+},(1.0 \mathrm{~g}, 1.51 \mathrm{mmol})$ dissolved in $2 \mathrm{~mL}$ deionized water was added dropwise ethyleneimine $(4.25 \mathrm{mmol})$ with the solution maintained at a $\mathrm{pH}$ of 3.2 with the addition of $70 \%$ perchloric acid. The reaction mixture was stirred at room temperature for $50 \mathrm{~h}$ with the $\mathrm{pH}$ maintained from 2-3, before the addition of $1.75 \mathrm{~mL}$ deionized water to solubilise precipitate. The product was precipitated by the addition of ice-cold ethanol and the precipitate washed with ethanol. The resulting mix of $N 1-2 A E-N A D^{+}$and $\mathrm{NAD}^{+}$was dissolved in water $(10 \mathrm{~mL})$ and adjusted to $\mathrm{pH} 6.5$ with $0.1 \mathrm{M} \mathrm{LiOH}$. The solution was stirred at $50^{\circ} \mathrm{C}$ for $7 \mathrm{~h}$ with the $\mathrm{pH}$ maintained at 6.5 before being lyophilized to yield the product, as a mixture of $N^{6}-2 A E-N A D^{+}$and $N A D^{+}$ (Supplementary Scheme 1).

\section{Synthesis of MAL-PEG ${ }_{24}-2 A E-N A D^{+}$.}

To a stirred solution of $N^{6}-2 A E-\mathrm{NAD}^{+} / \mathrm{NAD}^{+}\left(14.7 \mathrm{mg}\right.$ mix, approximately $0.0104 \mathrm{mmol} N^{6}-2 A E-\mathrm{NAD}^{+}$) in phosphate buffered saline (PBS; pH 7.4, $1.0 \mathrm{~mL}$ ) was added a solution of MAL-PEG ${ }_{24}-\mathrm{NHS}$ (17.4 mg, $0.0124 \mathrm{mmol}$ ) in PBS (1 mL). The solution was stirred at room temperature overnight (Supplementary Scheme 1). The mixture was analyzed by HPLC $\left(0 \rightarrow 50 \% \mathrm{CH}_{3} \mathrm{CN}+0.1 \%\right.$ TFA over $\left.18 \mathrm{~min}\right)$. Rt $17.8 \mathrm{~min}$ ESI+ found 662.62 (M/3, calcd 662.65) and 993.42 (M/2, calcd 993.98). The mixture was purified by preparative HPLC and fractions at Rt 17.8 min combined and lyophilized to yield pure MAL-PEG $24-2 A E-$ $\mathrm{NAD}^{+}$(5.4 mg, 26\%). 


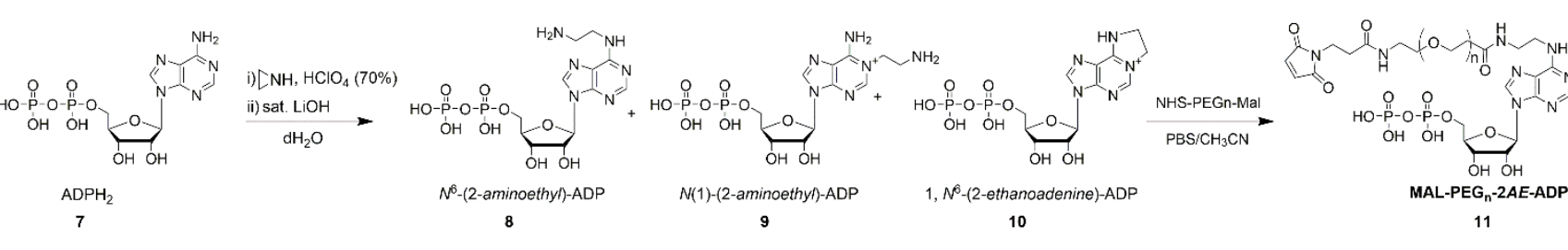

665
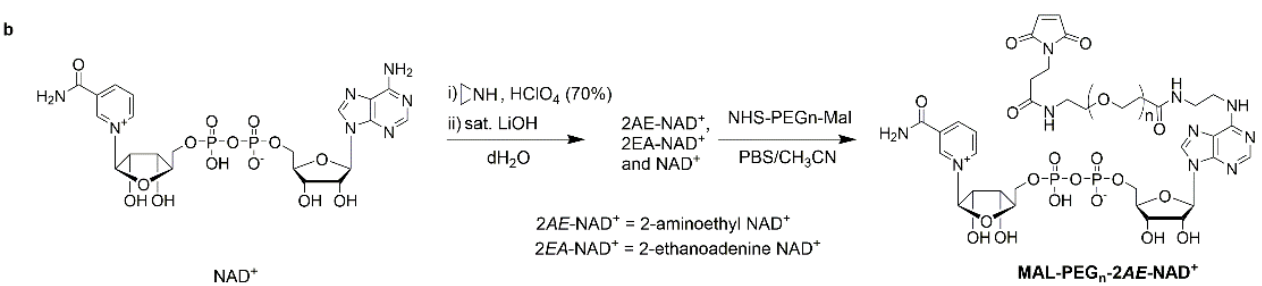

12

13

666

667

668

669

670

671

672

673

674

675

676

677

678

679

680

681

682

683

684

Supplementary Scheme 1. Synthesis of modified cofactors for tethering to nanomachine fusion proteins. a, Scheme for synthesis of MAL-PEG ${ }_{n}-2 A E-A D P$ (11) from ADP (7). b, Scheme for synthetic route to prepare MAL-PEG $n-2 A E-N A D^{+}(\mathbf{1 3})$ from $\mathrm{NAD}^{+}(\mathbf{1 2})$.

\section{Cofactor attachment}

\section{Tethering of MAL-PEG $24-2 A E-A D P$ to GlpK $_{T K}-A_{\text {Ace }} \mathrm{K}_{\mathrm{Ms}}-E{ } 2_{\mathrm{Aa}}$ in solution.}

IMAC purified GlpK $_{\mathrm{TK}}-$ AceK $_{\mathrm{Ms}}$-Est2 ${ }_{\mathrm{Aa}}$ was found to elute as high molecular weight protein and in PBS (Supplementary Figure 2). The IMAC purified protein was treated with TCEP $(0.1 \mathrm{mM})$ then reacted with 10 equivalents of MAL-PEG $24-2 A E-A D P$ without removal of the TCEP and washed with PBS. The tethered $2 A E-A D P-P E G_{24}-M A L-G l p K_{T K}-A_{c e} K_{M s}-E_{s t 2}{ }_{A a}$ was found to convert $10 \mathrm{mM}$ glycerol and $10 \mathrm{mM}$ acetyl phosphate to glycerol-3-phosphate with high efficiency (Supplementary Figure 3a).

\section{Tethering of MAL-PEG ${ }_{24}-2 A E-N A D^{+}$to $\mathrm{GPDD}_{\mathrm{Ec}}-\mathrm{NOX} \mathrm{X}_{\mathrm{Ca}}-\mathrm{Est2}_{\mathrm{Aa}}$ in solution.}

$\mathrm{G} \mathrm{PD}_{\mathrm{Ec}}-\mathrm{NOX}_{\mathrm{Ca}}-\mathrm{Est}_{\mathrm{Aa}}$ was desalted into PBS containing $0 \mathrm{mM}, 0.1 \mathrm{mM}$ or $1 \mathrm{mM}$ TCEP and reacted with 1-200 equivalents of MAL-PEG ${ }_{24}-2 A E-N A D^{+}$. The reaction mixtures were analyzed by SDS-PAGE and the conjugate from one condition (0.1 mM TCEP, 200 equivalents TCEP) analyzed by mass spectrometry. The tethered $2 A E-N A D^{+}-P_{E G}{ }_{24}-M A L-G 3 P D_{E c}-N O X_{C a}-E s t 2_{A a}$ was found to convert $10 \mathrm{mM}$ glycerol-3-phosphate and to DHAP with high efficiency (Supplementary Figure 3b). 

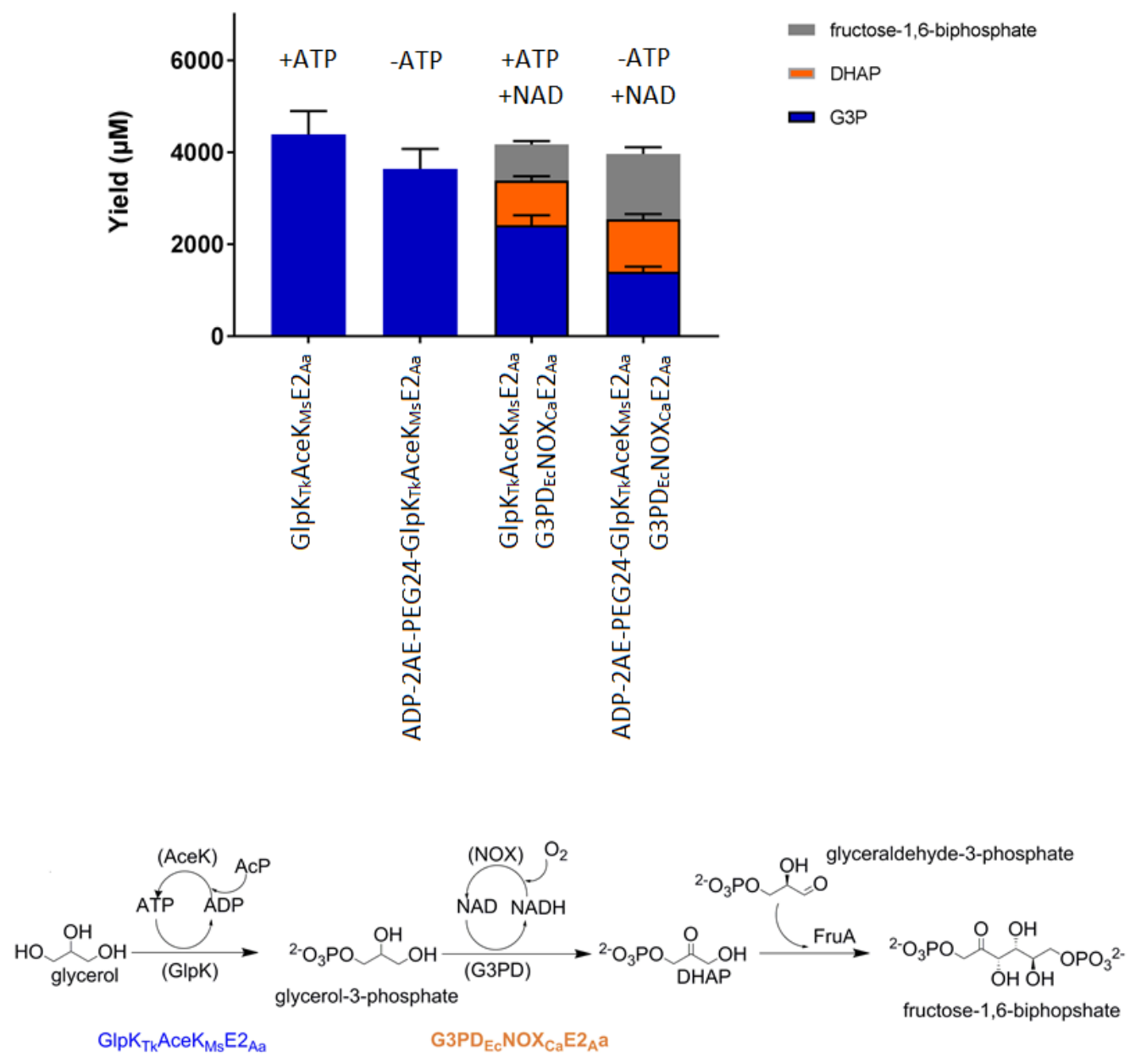

b

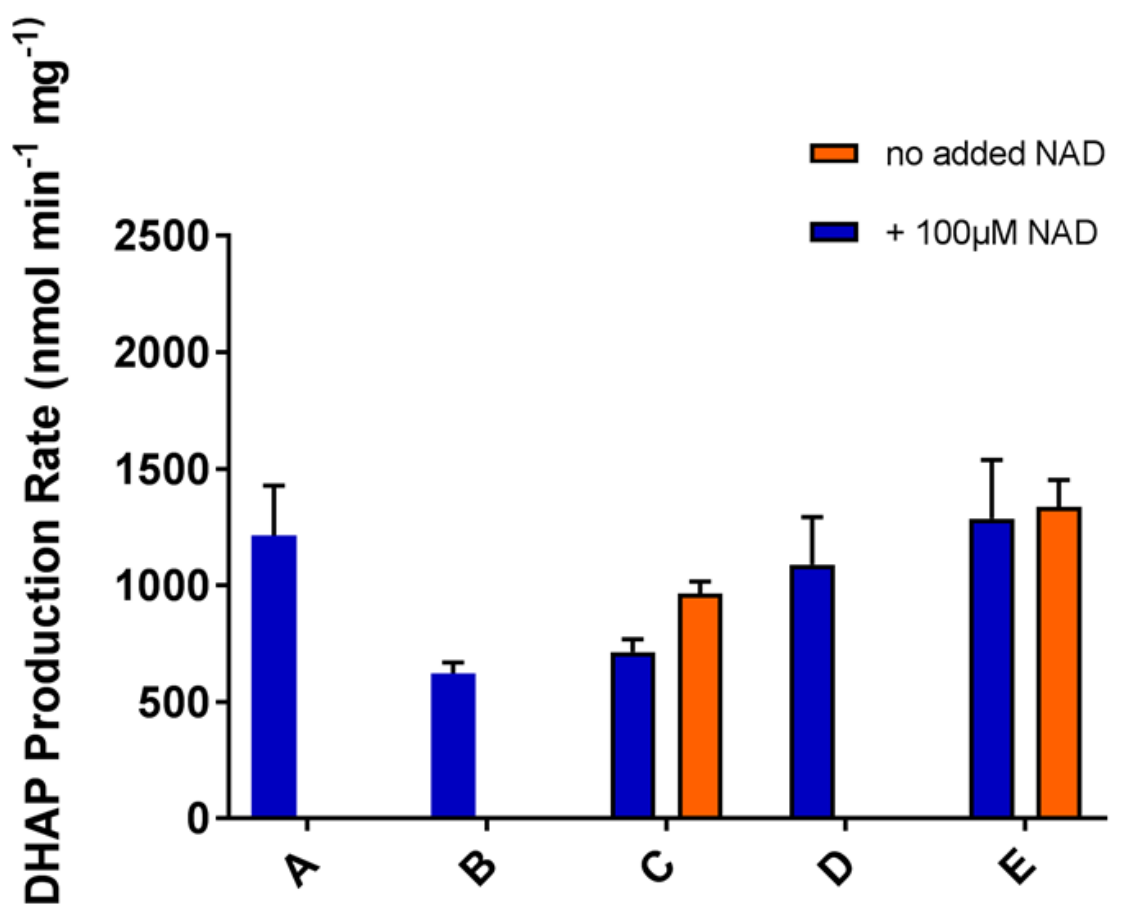


Supplementary Figure 3. Functional tethering of modified cofactors MAL-PEG ${ }_{24}-2 A E-A D P(a)$ and MAL-PEG ${ }_{24}-2 A E-N A D^{+}(b)$ to nanomachine fusion proteins. a, Glycerolkinase activity with and without the addition of $100 \mu \mathrm{M}$ ATP catalyzed by either $2 A E-A D P-P E G_{24}-M A L-G l p K_{T K}-A_{c e} K_{M s}-E 2_{A a}$ or by GlpK $K_{T k}-$ $A c e K_{M s}-E 2_{A a}$ was then coupled with glycerol-3-phosphate dehydrogenase activity (G3PD $\left.D_{E c}-N O X_{C a}-E 2_{A a}\right)$ and aldolase activity (FruAsc with glyceraldehyde-3-phosphate as added donor substrate) to demonstrate the production of fructose-1,6-biphosphate from $10 \mathrm{mM}$ glycerol using $2 A E-A D P-\mathrm{PEG}_{24}-$ MAL-GIpK $\mathrm{Tk}_{\mathrm{Tk}}-\mathrm{AceK}_{\mathrm{Ms}}-\mathrm{E} 2_{\mathrm{Aa}}$. A scheme of the three step reaction involved is illustrated beneath the graph. b, Glycerol-3-phosphate dehydrogenase activity (DHAP production rate) using $10 \mathrm{mM}$ glycerol-3phosphate with and without the addition of $100 \mu \mathrm{M} N A D^{+}$catalyzed by $2 A E-N A D^{+}-P^{2} G_{24}-M A L-G 3 P D_{E C^{-}}$ $N O X_{C a}-E 2_{A a}$ created under different reducing and tethering conditions: untethered control $G 3 P_{E_{E c}}$ $\operatorname{NOX}_{C_{2}-E 2_{A a}}(A), 1 \mathrm{mM}$ TCEP and 1 equivalent MAL-PEG $24-2 A E-N A D^{+}(B), 0.1 \mathrm{mM}$ TCEP and 1 equivalent MAL-PEG $24-2 A E-N A D^{+}(C)$, no TCEP and 1 equivalent MAL-PEG $24-2 A E-N A D^{+}$(D), $1 \mathrm{mM}$ TCEP and 5 equivalent MAL-PEG $24-2 A E-N A D^{+}(E)$. All reactions were conducted for 30 minutes at $37^{\circ} \mathrm{C}$, and products analysed by LCMS as described in analytical methods.

\section{Accurate mass determination of $M A L-P E G_{24}-2 A E-N A D^{+}$tethered to G3PD $_{\mathrm{Ec}}-\mathrm{NOX} \mathrm{X}_{\mathrm{Ca}}-\mathrm{Est}_{\mathrm{Aa}}$ by} LC-MS proteomics.

The accurate mass of $G 3 P D_{E c}-N A D_{\text {teth }}-N O X_{\mathrm{Ca}}-E s t 2_{A a}$ conjugates was determined by denaturing liquid chromatography-mass spectrometry (LC-MS). Protein samples were spiked with formic acid (FA) to a final concentration of $0.1 \%(\mathrm{v} / \mathrm{v})$ and separated by reverse-phased liquid chromatography on an UltiMate 3000 RSLC nano system (ThermoFisher Scientific) fitted with a $50 \times 4.6 \mathrm{~mm}, 5 \mu \mathrm{M}$ particle size, 300 Å pore size PLRP-S column (Agilent). Proteins were eluted at a flow of $250 \mu \mathrm{L} \mathrm{min}^{-1}$ by applying a linear 30 min gradient from 0 to $80 \%$ solvent B (mobile phase A: $0.1 \%(v / v)$ formic acid; mobile phase B: $90 \%(v / v)$ acetonitrile/0.1\% (v/v) formic acid) using an Apollo II electron spray ion source coupled to a microTOF-QIl mass spectrometer (Bruker). The instrument was calibrated in positive ion mode using ESI-L Low Concentration Tuning Mix (Agilent) and LC-MS raw data were processed and deconvoluted using the MaxEnt algorithm as part of Bruker Compass DataAnalysis version 4.3.

\section{Sample preparation and peptide sequencing by nanoUPLC-MSMS}

G3PD $D_{E c}-N A D_{\text {teth }}-N O X_{C a}-E s t 2_{A a}$ protein bands were manually excised from Coomassie-stained SDS-PAGE gels and subjected to manual in-gel reduction, alkylation and tryptic digestion. All gel samples were reduced with $10 \mathrm{mM}$ DTT (Sigma) for $30 \mathrm{~min}$, alkylated for $30 \mathrm{~min}$ with $50 \mathrm{mM}$ iodoacetamide (Sigma) and digested with $375 \mathrm{ng}$ trypsin gold (Promega) for $16 \mathrm{~h}$ at $37^{\circ} \mathrm{C}$. Peptides then were separated using an UltiMate 3000 RSLC nano system (ThermoFisher Scientific), utilizing a 60 min gradient on an Acclaim Pepmap 100 column ( $50 \mathrm{~cm} \times 75 \mu \mathrm{m}$ id with $3 \mu \mathrm{m}$ particles). High-resolution MS/MS data was obtained on an Orbitrap Fusion Lumos Mass Spectrometer operated in data-dependent mode, 

(

automatically switching between the acquisitions of a single Orbitrap MS scan (resolution, 120,000) every $3 \mathrm{~s}$ and the top-20 multiply charged precursors selected for EThcD fragmentation with a resolution of 30,000 for Orbitrap MS-MS scans.

\section{Mass spectra database searching}

Orbitrap MS/MS data was searched against a focused decoy database containing G3PD $\mathrm{Ec}_{\mathrm{C}}-\mathrm{NOX}_{\mathrm{Ca}}-\mathrm{Est}_{\mathrm{Aa}}$ and common contaminant protein sequences using the Byonic search engine (Protein Metrics) with tolerance of $5 \mathrm{ppm}$ for precursor ions and $10 \mathrm{ppm}$ for product ions. Enzyme specificity was tryptic and allowed for up to 2 missed cleavages per peptide. A Wildcard search with a range of +75 to $+2200 \mathrm{Da}$ facilitated confident peptide identification (< 1\% FDR) and spectrum counting of PEGylated cysteine residues. Variable modifications were set for $\mathrm{NH}_{2}$-terminal acetylation or protein $\mathrm{N}$-termini, oxidation of methionine or tryptophan, and carbamidomethyl modification of cysteine.

All of the cysteine containing peptides from the tryptic digest were able to be observed by mass spectrometry in the unconjugated sample, but the conjugated sample was missing the peptide corresponding to the linker cysteine, and instead peptides corresponding to the conjugated peptide were observed (Supplementary Figure 4).

(1) 


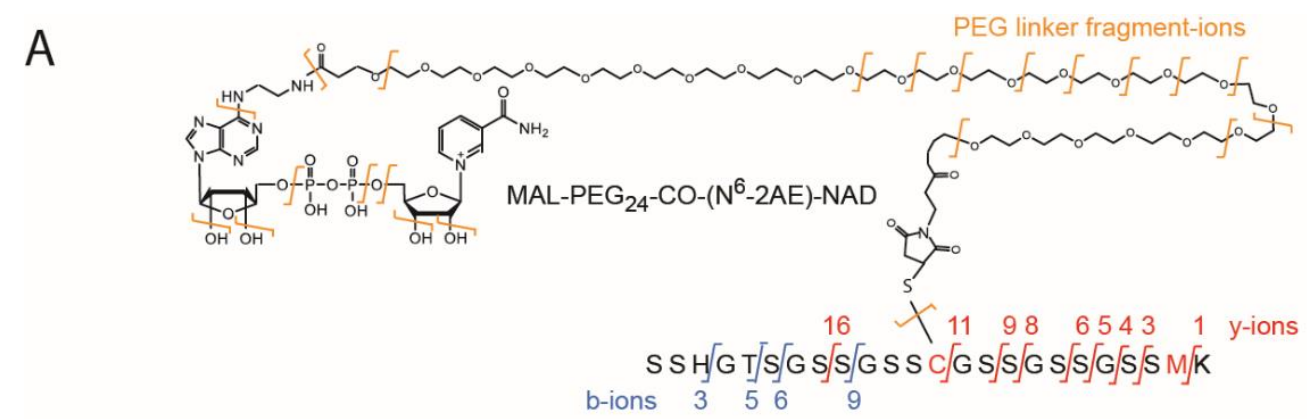

B

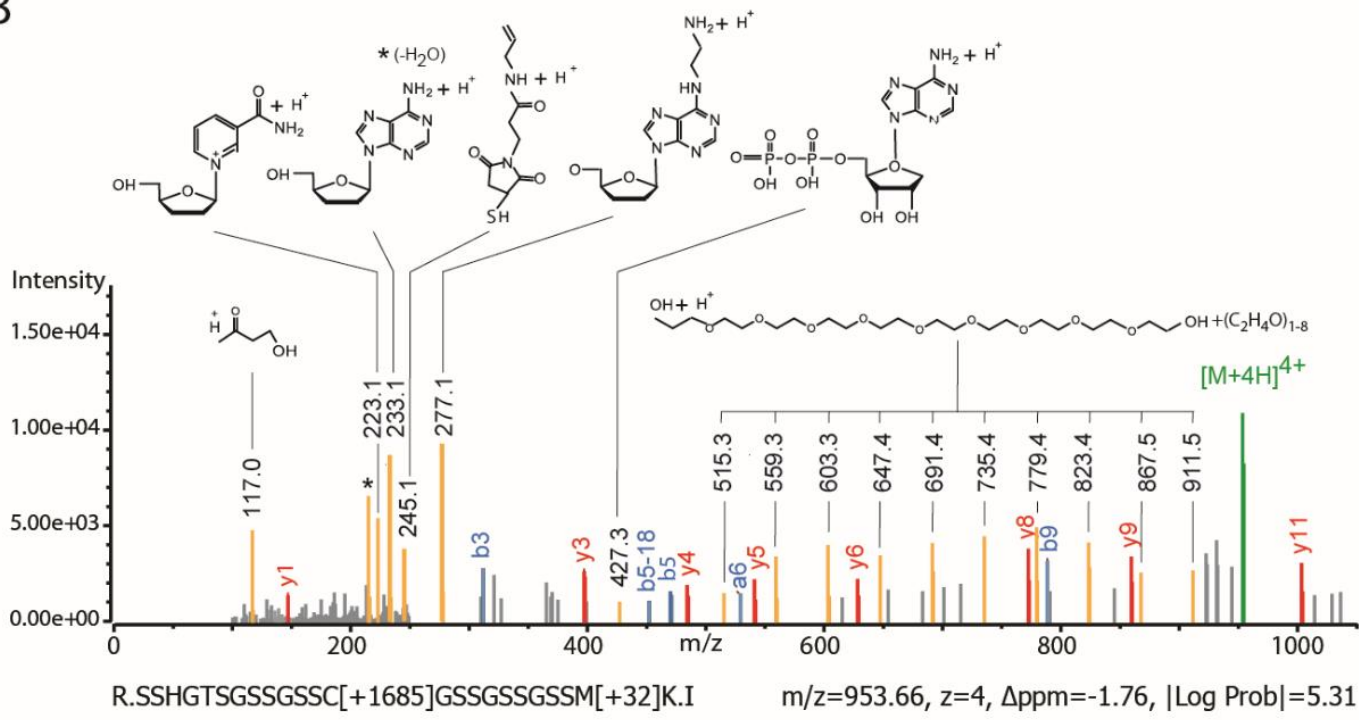

Supplementary Figure 4: Confirmation of functional Mal-PEG ${ }_{24}-2 A E-N A D^{+}$linkage to $\mathrm{G} \mathrm{PD}_{\mathrm{Ec}}-\mathrm{NOX}_{\mathrm{Ca}}{ }^{-}$ Est2 $_{\mathrm{Aa}}$ residue Cys369. a, Cartoon of the chemical structure of $M A L-P E G_{24}-2 A E-N A D^{+}$conjugated to $\mathrm{G} \mathrm{PD}_{\mathrm{Ec}}-\mathrm{NOX}_{\mathrm{Ca}}-\mathrm{Est}_{\mathrm{Aa}}$ residue Cys369 of tryptic peptide SSHGTSGSSGSSCGSSGSSGSSMK highlighting different MSMS fragment ions (peptide b-ions, blue; peptide y-ions, MAL-PEG ${ }_{24}-2 A E-N A D^{+}$CID ions, gold). b, Annotated LC-MSMS evidence spectrum for a high-scoring R.SSHGTSGSSGSSC[+1685]GSSGSSGSSM[+32]K.I peptide highlighting peptide $b$ - and $y$-ions (blue, red) as well as the observed masses and chemical structures of matching MAL-PEG ${ }_{24}-2 A E-N A D^{+}$fragments. The observed $+1685 \mathrm{Da}$ mass modification and fragmentation pattern is consistent with $G 3 P \mathrm{DEC}_{\mathrm{Ec}}-\mathrm{NOX}_{\mathrm{Ca}^{-}}$ Est2 ${ }_{\mathrm{Aa}}$ Cys396 being tethered to a functional MAL-PEG $24-2 A E-N A D^{+}$linker.

Nanomachine immobilization onto agarose beads and nanomachine conjugation to modified cofactors.

Synthesis of thiohexyltrifluoroketone (hTFK). anhydrous dichloromethane $(8 \mathrm{~mL})$ under a nitrogen atmosphere. Bromotrifluoroacetone $(0.415 \mathrm{~mL}$, 
$0.4 \mathrm{mmol}$ ) was then added dropwise. Reaction was monitored by TLC. The reaction mixture was stirred under $\mathrm{N}_{2}$ for 5 days at room temperature and then poured into $50 \mathrm{~mL}$ water. After extraction with ether $(3 \times 30 \mathrm{~mL})$, the organic solvent was dried $\left(\mathrm{MgSO}_{4}\right)$ and the solvent removed under reduced pressure. Thiohexyltrifluoroketone was characterised by LC-MS; aHPLC (20 - 80\% gradient MeCN into $\mathrm{H}_{2} \mathrm{O}, 0.1 \%$ TFA) gave a single peak at $6.6 \mathrm{~min}(\lambda=214 \mathrm{~nm}),>90 \%$ purity, ESI (negative scan mode) found 259.16 amu; calculated MW = 260.33. hTFK could be used directly in loading the DVS-modified beads.

\section{Synthesis of hTFK-vinylsulfone activated beads.}

4\% crosslinked agarose (Sepharose CL-4B, GE Healthcare) was functionalized by treatment with divinylsulfone (DVS) to yield the vinylsulfone decorated agarose as an aqueous slurry with vinyl sulfones at approximately $1 \mathrm{mmol} \mathrm{mL}^{-1}$ of slurry. To $500 \mathrm{~g}$ of damp drained Sepharose CL-4B was added $500 \mathrm{~mL}$ of $0.5 \mathrm{M} \mathrm{Na}_{2} \mathrm{CO}_{3}(\mathrm{pH} \mathrm{12)}$ and $5000 \mu \mathrm{L}$ divinylsulfone. The resulting suspension was stirred gently for $70 \mathrm{~min}$ at room temperature before being washed extensively with water. The solution was stored as a $1: 1 \mathrm{w} / \mathrm{v}$ slurry in $50 \%$ ethanol/water. This activated DVS-agarose was then reacted with thiohexyltrifluoroketone (hTFK) at approximately 5 molar percent ratio for between $6 \mathrm{~h}$ and overnight before capping all remaining vinyl sulfone functionalities with 2-mercaptoethanol. Saturated $\mathrm{NaHCO}_{3}$ solution $(20 \mathrm{~mL})$, and thiohexyl trifluoroketone $(1.2 \mathrm{~mL}$ ethanol solution containing $26 \mathrm{mg}$ of compound, $0.1 \mathrm{mmol}$, $5 \%$ loading) were added to the divinyl sulfone resin ( $200 \mathrm{~mL}, 16-20 \mathrm{mmol}, 50 \%$ slurry in 1:1 ethanol/water) and stirred at room temperature for $2 \mathrm{~h}$; excessive reactive sites were blocked by the addition of beta-mercaptoethanol $(2.8 \mathrm{~mL}, 40 \mathrm{mmol})$ and washed with $50 \%$ ethanol/water until no smell was evident. The hTFK-loaded agarose gel obtained was filtered, washed and stored as a 1:1 slurry in 50\% ethanol/water for further use. The synthesis scheme is summarized below (Supplementary Scheme 2).

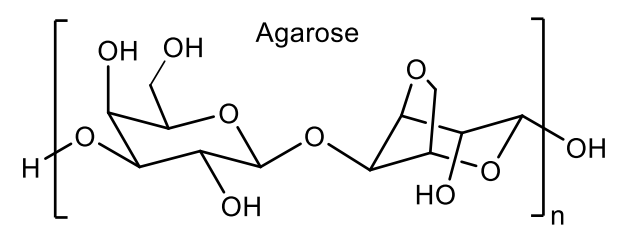

1) $\mathrm{HS}^{\mathrm{hTFK}} \mathrm{S} \overbrace{\mathrm{CF}_{3}}^{\mathrm{O}}$

2) excess 2-mercaptoethanol sat. aq. $\mathrm{NaHCO}_{3}$ $50 \%$ water/ethanol
DVS, $0.5 \mathrm{M} \mathrm{Na}_{2} \mathrm{CO}_{3}$

pH 12

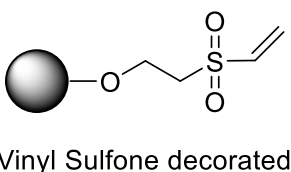

Agarose Bead

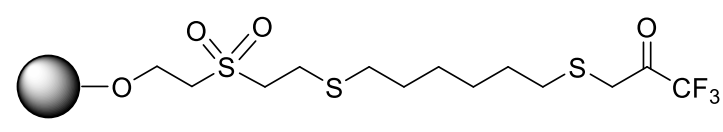

hTFK decorated Agarose Bead 
Supplementary Scheme 2. Scheme for the preparation of hTFK decorated agarose beads via vinylsulfone activation.

Immobilization of GIpK $\mathrm{Tk}_{\mathrm{Tk}}-\mathrm{Ace}_{\mathrm{Ms}}-\mathrm{Est2}_{\mathrm{Aa}}$ to Sepharose-DVS-hTFK.

791

792

A lysate from $8 \mathrm{~g} \mathrm{GlpK}_{\mathrm{TK}}-$ AceK $_{\mathrm{Ms}}-$ Est2 $_{\mathrm{Aa}}$ cells prepared as described previously (200 $\mathrm{mL}$ ) was added to $25 \mathrm{~g}$ Sepharose-DVS-hTFK, and the slurry mixed at $4^{\circ} \mathrm{C}$. The loss of esterase activity in the supernatant was monitored and after $2.5 \mathrm{~h}$ there was no further loss of esterase activity, and the adsorbent

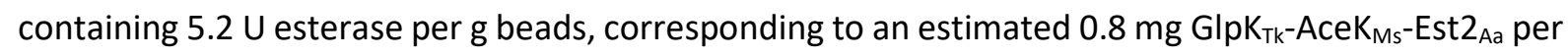
$\mathrm{g}$, or $6 \mathrm{nmol} \mathrm{GlpK}_{\mathrm{Tk}}-$ AceK $_{\mathrm{Ms}}-\mathrm{Est2}_{\mathrm{Aa}}$ per gram, was filtered and washed.

\section{Tethering of MAL-PEG ${ }_{24}-2 A E-A D P$ to immobilized Sepharose-DVS-TFK-GIpK ${ }_{T K}-A_{c e} K_{M s}-E_{s t 2}{ }_{A a}$.}

The Sepharose-DVS-GIpK $\mathrm{Tk}_{\mathrm{T}}-\mathrm{AceK}_{\mathrm{Ms}}-\mathrm{Est}_{\mathrm{Aa}}(25 \mathrm{~g})$ was incubated in Tris-buffered saline $\mathrm{pH} 7.0$ containing $1 \mathrm{mM}$ TCEP for $1.5 \mathrm{~h}$ at $4{ }^{\circ} \mathrm{C}$ before being washed with extensively degassed PBS containing $0.5 \mathrm{mM}$ EDTA. An equal volume of this buffer was added to the slurry together with $0.8 \mu \mathrm{mol} M A L-P E G_{24}-2 A E-$ ADP and the mixture allowed to react for $6 \mathrm{~h}$ at $4{ }^{\circ} \mathrm{C}$ with mixing. The slurry was then filtered and washed with TBS.

\section{Immobilization of G3PD $\mathrm{Ec}_{\mathrm{Ec}}-\mathrm{NOX}_{\mathrm{Ca}}-\mathrm{Est2}_{\mathrm{Aa}}$ to Sepharose-DVS-hTFK.}

To lysate from $10.6 \mathrm{~g}$ G3PDEc-NOX $\mathrm{Ca}-\mathrm{Est}_{\mathrm{Aa}}$ cell paste prepared as described for the purification of $G 3 P D_{E c}-N O X_{C_{a}-E s t} 2_{A a}$ above was added $80 \mathrm{~g}$ Sepharose-DVS-hTFK and the mixture stirred gently for $100 \mathrm{~min}$ at $4{ }^{\circ} \mathrm{C}$. The slurry was filtered and washed with extensively degassed PBS containing $0.5 \mathrm{mM}$ EDTA and $10 \mu \mathrm{M}$ TCEP.

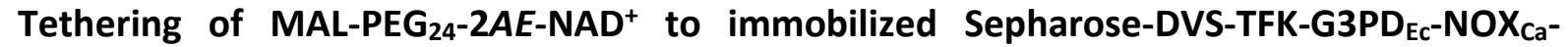 Est2 Aa.}

To $35 \mathrm{~mL}$ of the slurry was added an equal volume of this buffer together with $580 \mathrm{nmol}$ MAL-PEG $24^{-}$ $2 A E-\mathrm{NAD}^{+}$and the mixture allowed to react at $4{ }^{\circ} \mathrm{C}$ with mixing for $30 \mathrm{~min}$ before being filtered and washed with PBS containing 1 mM TCEP. 


\section{Reactor Assembly}

817

818

819

820

821

822

823

824

825

826

827

828

829

830

831

832

833

834

835

836

837

838

839

840

841

842

843

844

845

846

In line with the intended modular, hierarchal organization of our nanomachine technology, we optimized each nanomachine reactor individually and then combined them into a serial multi-enzyme D-fagomine nanofactory as shown in Figure 2.

\section{The Phosphotransfer Reactor}

For the preparation of the phosphotransfer reactor (Figure 2), $40 \mathrm{mg}$ of $\mathrm{GlpK}_{T k}-\mathrm{AceK}_{M s}-\mathrm{Est2}_{A a}$ protein (296 nmol) was immobilized onto $25 \mathrm{~g}$ of Sepharose-hexyl-DVS-TFK beads. The immobilized GlpK Tk- $^{-}$ AceK $_{M s}$-Est2 $2_{A a}$ was treated with $0.1 \mathrm{mM}$ TCEP, washed with PBS containing $0.5 \mathrm{mM}$ EDTA then reacted with six equivalents MAL-PEG ${ }_{24}-2 A E-A D P$ for $6 \mathrm{~h}$ at $4{ }^{\circ} \mathrm{C}$ before being washed with reaction buffer $(0.2$ $\mathrm{M}$ sodium citrate buffer $\mathrm{pH}$ 7.9). The resultant immobilized cofactor-tethered nanomachine beads were analyzed for glycerol kinase activity in the presence and absence of ATP in batch reactions, and demonstrated to have $\sim 30 \%$ tethering efficiency (activity without added ADP calculated as the percentage of activity with added ADP). The resultant immobilized nanomachine beads were then packed into a $25 \mathrm{~mm} * 15 \mathrm{~mm}$ Benchmark column (Kinesis, Australia) to a packed bed volume of 21.2 $\mathrm{mL}$ and performance assessed in a flow reactor system.

A bioreactor packed with the immobilized GlpK $_{T K}-\mathrm{ATP}_{\text {teth }}-\mathrm{AceK}_{M s}-\mathrm{Est}_{A a}$ nanomachine beads was found to convert $10 \mathrm{mM}$ glycerol and $10 \mathrm{mM}$ acetyl phosphate to G3P and acetate with approximately $60 \%$ efficiency at the optimal flow rate of $0.25 \mathrm{~mL} \mathrm{~min}^{-1}$ (Supplementary Figure 5a). This resulted in a space time yield of $70 \mathrm{mg} \mathrm{G} \mathrm{P} \mathrm{L} \mathrm{L}^{-1} \mathrm{hr}^{-1} \mathrm{mg}^{-1}$ protein. The bioreactor stability was further assessed by continuing to run the phosphotransfer reactor for a total time of 870 minutes resulting in a total 14222 turnovers of the tethered cofactor (Figure 3).

\section{The Oxidation Reactor}

For the preparation of the $\mathrm{G} \mathrm{PD}_{\mathrm{Ec}}-\mathrm{NOX}_{\mathrm{Ca}}-\mathrm{Est}_{\mathrm{Aa}}$ oxidation reactor (step 2 in Figure 2), $80 \mathrm{mg}$ of G3PDECNOXCa-Est2Aa protein (647 nmol; 1260 esterase U) was immobilized onto $80 \mathrm{~g}$ of Sepharose-hexylDVS-TFK. The immobilized G3PDEc-NOXCa-Est2Aa was treated with TCEP, washed with degassed, sparged PBS containing $0.5 \mathrm{mM}$ EDTA then reacted with six equivalents MAL-PEG ${ }_{24}-2 A E-N A D^{+}$for $6 \mathrm{~h}$ at $4{ }^{\circ} \mathrm{C}$ before being washed with PBS. The resultant immobilized cofactor-tethered nanomachine beads were analyzed for glycerol-3-phosphate dehydrogenase activity in the presence and absence of 
$847 \mathrm{NAD}^{+}$in batch reactions, and demonstrated to have 80\% tethering efficiency (activity without added

$848 \mathrm{NAD}^{+}$calculated as the percentage of activity with added $\left.N A D^{+}\right)$. The resultant immobilized

849 nanomachine beads were then packed into a $250 \mathrm{~mm} \times 15 \mathrm{~mm}$ Benchmark column (Kinesis, Australia)

850 to a packed bed volume of $28.3 \mathrm{~mL}$ and assessed in a flow reactor system.

851 A column packed with the adsorbent was found to convert $10 \mathrm{mM} \mathrm{G3P}$ to DHAP with about $40-50 \%$

852 efficiency at a flow rate of $0.25 \mathrm{~mL} \mathrm{~min}^{-1}$ (Supplementary Figure $5 \mathrm{~b}$ ). This resulted in a space time yield

853 of $2.60 \mathrm{mg} \mathrm{DHAP} \mathrm{L}^{-1} \mathrm{hr}^{-1} \mathrm{mg}^{-1}$ protein. The bioreactor stability was further assessed by continuing to

854 run the oxidation reactor for a total time of 6000 minutes resulting in a total 1843 turnovers of the

855 tethered cofactor (Figure 3).

856

857 The Aldol Addition Reactor

858 For the preparation of immobilized nanomachine beads for the aldol addition reactor, $20 \mathrm{mg}$ of FruAsc-

859 Est2 $2_{A a}$ protein was reacted with $20 \mathrm{~g}$ of Sepharose-hexyl-DVS-TFK beads. The resultant immobilized

860 aldolase nanomachine beads were then packed into a $150 \mathrm{~mm} \times 15 \mathrm{~mm}$ Benchmark column (Kinesis,

861 Australia) to a final depth of $10 \mathrm{~cm}(17.7 \mathrm{~mL}$ packed bed volume) and assessed in a flow reactor system.

862 Optimal flow rate was assessed for the aldol reactor and found to be $0.1 \mathrm{~mL} \mathrm{~min}^{-1}$, with approximately

$86386 \%$ and $98 \%$ conversion of $5 \mathrm{mM} \mathrm{N}$-Cbz-3-aminopropanal and $5 \mathrm{mM}$ DHAP respectively, under these conditions (Supplementary Figure 5c). 
bioRxiv preprint doi: https://doi org/10.1101/568972; this version posted March 5, 2019. The copyright holder for this preprint (which was not certified by peer review) is the author/funder, who has granted bioRxiv a license to display the preprint in perpetuity. It is made available under aCC-BY-NC-ND 4.0 International license.

a

Phosphotransfer reactor

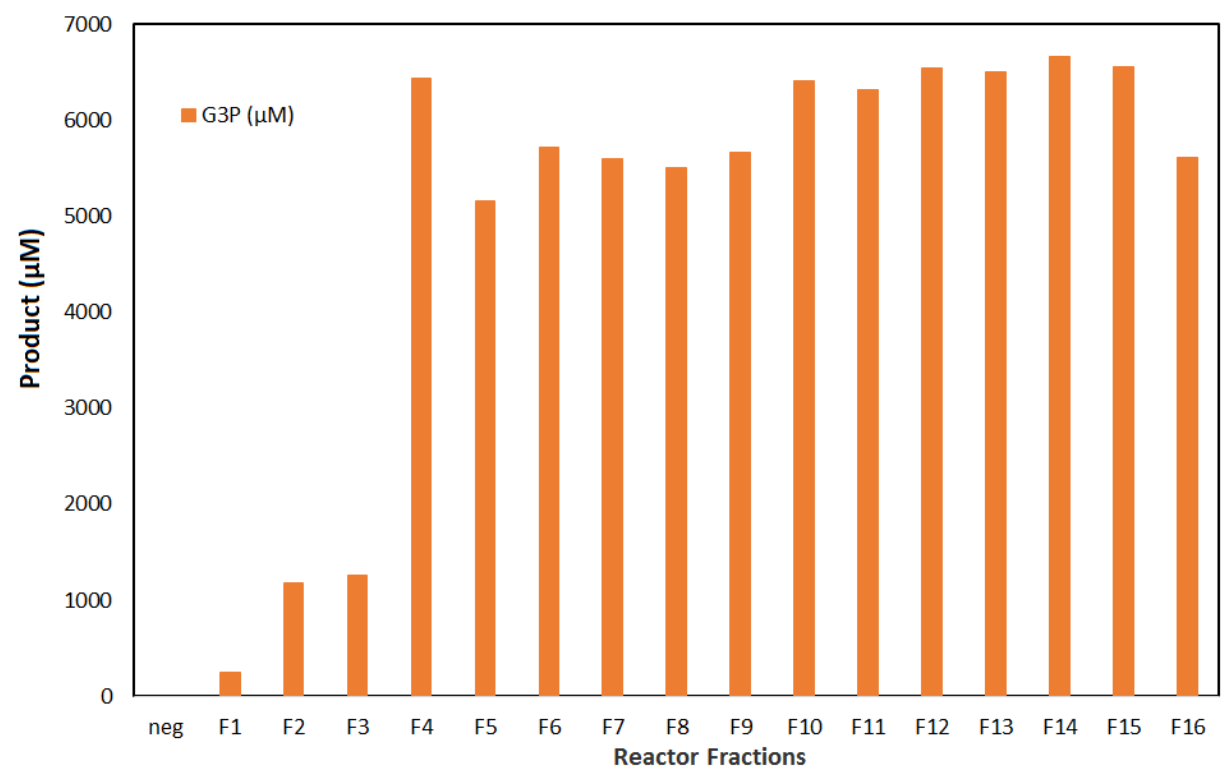

b Oxidation reactor

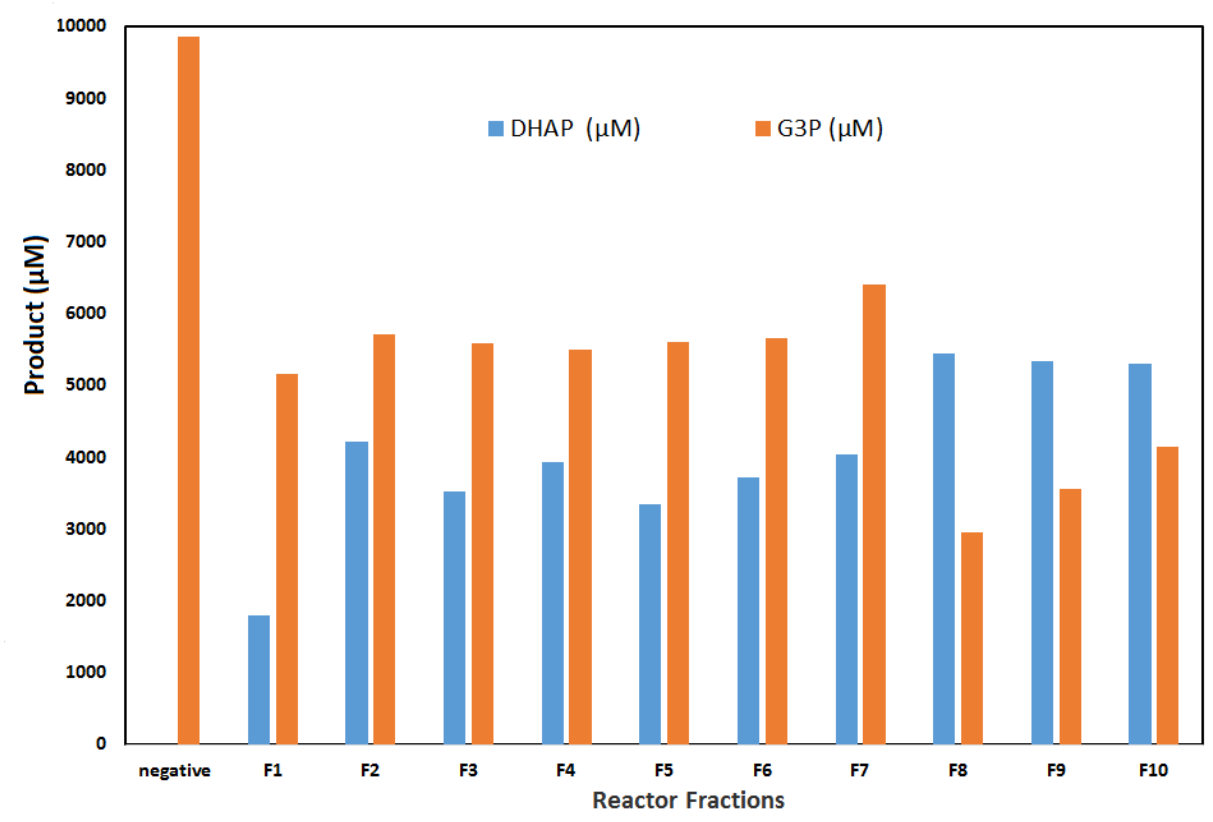

c Aldol Addition Reactor

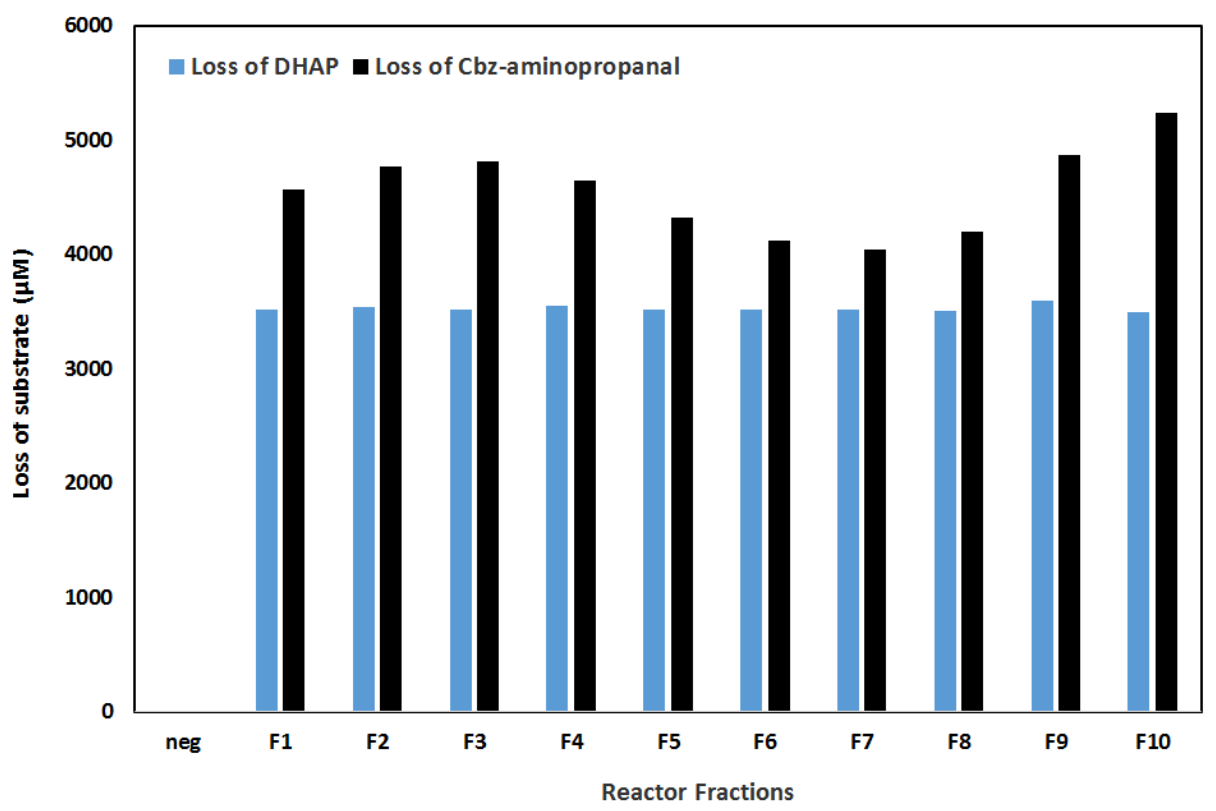


bioRxiv preprint doi: https://doi.org/10.1101/568972; this version posted March 5, 2019. The copyright holder for this preprint (which was not certified by peer review) is the author/funder, who has granted bioRxiv a license to display the preprint in perpetuity. It is made available under aCC-BY-NC-ND 4.0 International license.

Supplementary Figure 5. Assembly and testing of each of the nanomachine reactors used to assemble the Nanofactory. a, Phosphotransfer Reactor: Conversion of glycerol and acetyl phosphate (10 mM each) to G3P and acetate by immobilized $\mathrm{GlpK}_{\mathrm{Tk}}-\mathrm{ATP}_{\text {teth }}-\mathrm{AceK}_{\mathrm{Ms}}-\mathrm{Est}_{\mathrm{Aa}}$ in a packed bed reactor column $(1.5 \mathrm{~cm}$ id, $12 \mathrm{~cm})$ run at a flow rate of $0.25 \mathrm{~mL} \mathrm{~min}^{-1}$, as determined by LCMS analysis of $5 \mathrm{~mL}$ fractions. $\mathbf{b}$, Oxidation reactor: conversion of G3P to DHAP in a flow reactor. The immobilized $G 3 \mathrm{PD}_{\mathrm{Ec}}{ }^{-}$ $N A D_{\text {teth }}-N_{0 X} X_{C a}-E s t 2_{A a}$ nanomachine beads were used to prepare a packed bed reactor column $(1.5 \mathrm{~cm}$ id $\times 16.5 \mathrm{~cm}$ ). $10 \mathrm{mM} \mathrm{G3P} \mathrm{pH} 8$ was passed through the column at a flow rate of $0.25 \mathrm{~mL} \mathrm{~min}^{-1}$ and the amount of G3P remaining and DHAP produced determined by LCMS for $5 \mathrm{~mL}$ fractions F1 to F10. c, Aldol addition reactor with $\mathrm{Fru}_{\mathrm{sc}}-\mathrm{E} 2_{\mathrm{Aa}}$ : conversion of $\mathrm{Cbz}$-aldehyde and DHAP into $\mathrm{N}-\mathrm{Cbz}-3 \mathrm{~S}, 4 R$-ADHOP in a flow reactor. The immobilized $\mathrm{Fru}_{\mathrm{sc}}-\mathrm{E} 2_{\mathrm{Aa}}$ nanomachine beads prepared in the presence of $10 \mu \mathrm{M}$ TCEP were used to prepare a packed bed reactor column $(1.5 \mathrm{~cm}$ id $\times 16.5 \mathrm{~cm}) .5 \mathrm{mM} \mathrm{N}-\mathrm{Cbz}-3-$ aminopropanal and DHAP in $50 \mathrm{mM}$ citrate buffer $\mathrm{pH} 7$ was passed through the column at a flow rate of $0.1 \mathrm{~mL} \mathrm{~min}^{-1}$ and the amount of DHAP and $\mathrm{N}$-Cbz-3-aminopropanal remaining quantified by LCMS for $5 \mathrm{~mL}$ fractions F1 to F10.

\section{Enzyme activity assays (In batch and in flow)}

\section{Glycerol kinase activity}

Glycerol kinase assays were performed at room temperature in $1 \mathrm{~mL}$ volume with direct detection of ADP and ATP by HPLC analysis of reaction supernatant. A typical reaction contained $1 \mathrm{mM}$ glycerol, $10 \mathrm{mM} \mathrm{MgCl}$, $50 \mathrm{mM} \mathrm{NaHCO}_{3}$ buffer $\mathrm{pH}$ 9.0, $1 \mathrm{mM}$ ATP with approximately $2 \mu \mathrm{mL}^{-1}$ enzyme $(\sim 35 \mathrm{nM})$. Kinetics were determined by varying the concentrations of ATP or glycerol whilst maintaining the other in excess, and kinetic determinants calculated using Hyper ${ }^{\mathrm{TM}}$ (J.S. Easterby, Liverpool University) or GraphPad Prism (GraphPad Software Inc., USA). Substrate and cofactor concentrations ranged from 0.1 to $10 \times K_{\mathrm{M}}$.

\section{Acetate kinase activity.}

Acetate kinase assays were conducted in the same manner as the glycerol kinase assays described above, replacing ATP with ADP, and glycerol with acetyl phosphate or phosphoenol pyruvate. Kinetics were determined by varying the concentrations of ADP or acetyl phosphate or phosphoenol pyruvate whilst maintaining the other components in excess, and kinetic determinants calculated using Hyper (J.S. Easterby, Liverpool University). Substrate and cofactor concentrations ranged from 0.1 to $10 \times K_{\mathrm{M}}$.

\section{Glycerol-3-phosphate dehydrogenase activity}

Glycerol-3-phosphate (G3P) dehydrogenase activity was determined from the oxidation of glycerol-3phosphate to DHAP in $50 \mathrm{mM}$ sodium phosphate $\mathrm{pH} 9.0$ for individual enzyme assays, or at $\mathrm{pH} 8.0$ for combined multienzyme reactions, with the reaction progress followed by monitoring the production of NADH spectroscopically at $340 \mathrm{nM}\left(\varepsilon_{340 \mathrm{~nm}} 6.22 \mathrm{mM}^{-1} \mathrm{~cm}^{-1}\right)$, or by direction detection of both G3P 
904

905

906

907

908

909

910

911

912

913

914

915

916

917

918

919

920

921

922

923

924

925

926

927

928

929

930

931

932

(substrate) and DHAP (product) using LCMS (see Analytical methods and Supplementary Figure 6), with one unit of glycerol-3-phosphate activity defined as the amount required to oxidize $1 \mu \mathrm{mol} G 3 \mathrm{P}$ in one minute at ambient temperature. Kinetics were determined by varying the concentration of G3P and $\mathrm{NAD}^{+}$from 0.1 to $10 \times K_{\mathrm{M}}$ and kinetic determinants were calculated using $\mathrm{Hyper}^{\mathrm{TM}}$ (J.S. Easterby, Liverpool University) or GraphPad Prism (GraphPad Software Inc., USA).

\section{NADH oxidase activity (untethered).}

NADH oxidase activity was determined from the oxidation of $0.1 \mathrm{mM} \mathrm{NADH}$ in $50 \mathrm{mM}$ sodium phosphate $\mathrm{pH} 7$ containing $1 \mathrm{mg} \mathrm{mL}^{-1} \mathrm{BSA}$, with the loss of NADH monitored spectroscopically at $340 \mathrm{nM}\left(\varepsilon_{340 \mathrm{~nm}} 6.22 \mathrm{mM}^{-1} \mathrm{~cm}^{-1}\right)$, with one unit of NADH oxidase activity defined as the amount required to oxidize $1 \mu \mathrm{mol} N A D H$ in one minute at ambient temperature. Kinetics were determined by varying the concentration of $\mathrm{NADH}$ from 0.1 to $10 \times K_{\mathrm{M}}$ and kinetic determinants were calculated using Hyper $^{\text {TM }}$ (J.S. Easterby, Liverpool University) or GraphPad Prism (GraphPad Software Inc., USA).

\section{Esterase activity.}

Esterase activity was determined from the hydrolysis of $p$-nitrophenyl acetate (Sigma) in $50 \mathrm{mM}$ sodium phosphate $\mathrm{pH} 7$ containing $1 \mathrm{mg} \mathrm{mL}^{-1} \mathrm{BSA}$ and with a typical reaction containing $0.4 \mathrm{mM} \mathrm{p}$ nitrophenyl acetate. The hydrolysis of $p$-nitrophenyl acetate was determined spectroscopically by the increase in absorbance at $405 \mathrm{~nm}$ due to production of $p$-nitrophenol $\left(\varepsilon_{405} \mathrm{~nm} 18 \mathrm{mM}^{-1} \mathrm{~cm}^{-1}\right)$, with one unit of esterase activity defined as the amount required to hydrolyze $1 \mu \mathrm{mol} p$-nitrophenyl acetate in one minute at ambient temperature. Kinetics were determined by varying the concentration of substrate from 0.1 to $10 \times K_{\mathrm{M}}$ and kinetic determinants were calculated using Hyper $^{\mathrm{TM}}$ (J.S. Easterby, Liverpool University) or GraphPad Prism (GraphPad Software Inc., USA).

\section{Analytical Methods}

\section{HPLC separation of ATP and ADP.}

HPLC separation was conducted using an Agilent Eclipse XDB column ( $50 \mathrm{~mm} \times 4.6 \mathrm{~mm}$ ) with isocratic elution using $75 \%$ solvent $A$ and $25 \%$ solvent B. Solvent A: $20 \mathrm{mM}$ tetrabutylammonium phosphate 
933 (TBAP) in $10 \mathrm{mM}$ ammonium phosphate buffer $\mathrm{pH}$ 4.0; solvent $\mathrm{B}$ : acetonitrile. Flow rate $1 \mathrm{~mL}$ per minute, detection at $240 \mathrm{~nm}$ using diode array detector (Agilent Technologies, USA). Peaks eluted at the following retention times: ADP $1.2 \mathrm{~min}$, ATP $1.8 \mathrm{~min}$. aldol products.

939 G3P and DHAP were separated using a modification of the method described in Prieto-Blanc et al., $9402010^{32}$. Chromatographic conditions were SIELC ObeliscN column (100 mm x $2.1 \mathrm{~mm}$ ) with isocratic 941 elution using 20\% mobile phase A, 80\% mobile phase B for 5 minutes. Mobile phase A: $25 \mathrm{mM}$ 942 ammonium formate $\mathrm{pH}$ 4.0; mobile phase B: acetonitrile. Mass spectrophotometric detection was 943 conducted using API-ES negative mode with an Agilent 6120 Quadropole LCMS. Compounds were 944 qualitatively detected by ion scanning in both positive and negative mode using know standards, and 945 then quantified based on selected ion monitoring (SIM) monitoring of relevant ions. Glycerol-3946 phosphate was quantified by selected ion monitoring of ion [M] $\mathrm{m} / \mathrm{z}=171.06$, DHAP quantified by 947 selected ion monitoring of ion $[\mathrm{M}]^{-} \mathrm{m} / \mathrm{z}=169.04$, after establishing suitable selected ions using positive 948 and negative scanning of standards. Quantitation was based on comparison to standard calibration 949 curves produced in the same manner. $\mathrm{N}$-Cbz-3-aminopropanal and $\mathrm{N}$-Cbz-3S,4R-ADHOP were 950 detected and quantified using absorbance $A_{214 n m}$ and selected ion monitoring of ion $[\mathrm{M}-\mathrm{H}]^{-} \mathrm{m} / \mathrm{z}=$ 951376.09 (N-Cbz-3S,4R-ADHOP) by comparison with calibration curves made using a synthesised 952 standard (Supplementary Figure 6). The $\mathrm{N}-\mathrm{Cbz}-3 \mathrm{~S}, 4 R$-ADHOP standard was synthesised from DHAP 953 (Sigma-Aldrich) and $\mathrm{N}$-Cbz-3-aminopropanal (Sigma-Aldrich) using enzymatic aldol addition with 954 purified FruAsc and the resultant $N$-Cbz-3S,4R-ADHOP was purified essentially as described by Castillo 955 and colleagues ${ }^{17}$. ${ }^{1} \mathrm{H}$-NMR spectroscopy confirmed the purity of the standard (Supplementary Figure 956 6c) and this standard was then used to identify and quantitate the $N$-Cbz-3S,4R-ADHOP produced from 957 the nanofactory by selected ion monitoring. 
bioRxiv preprint doi: https://doi.org/10 1101/568972; this version posted March 5, 2019. The copyright holder for this preprint (which was

not certified by peer review) is the author/funder, who has granted bioRxiv a license to display the preprint in perpetuity. It is made available under aCC-BY-NC-ND 4.0 International license.

a
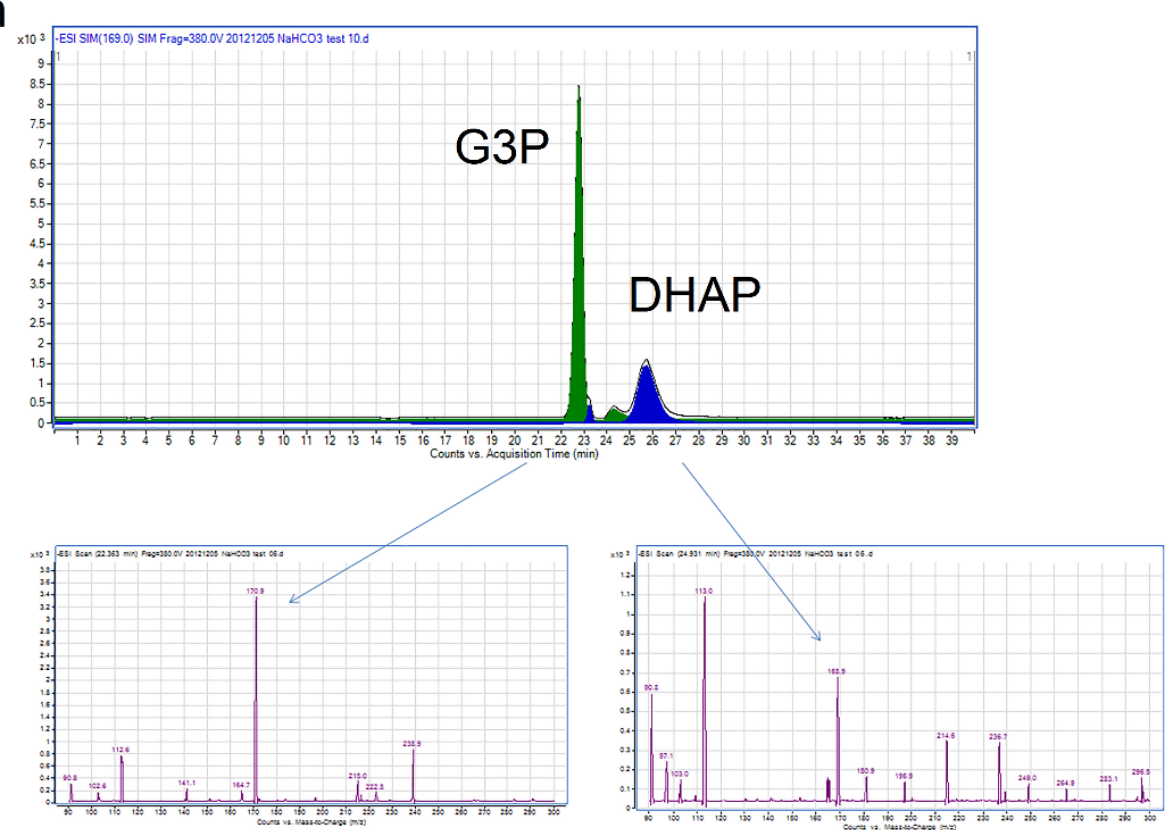

b
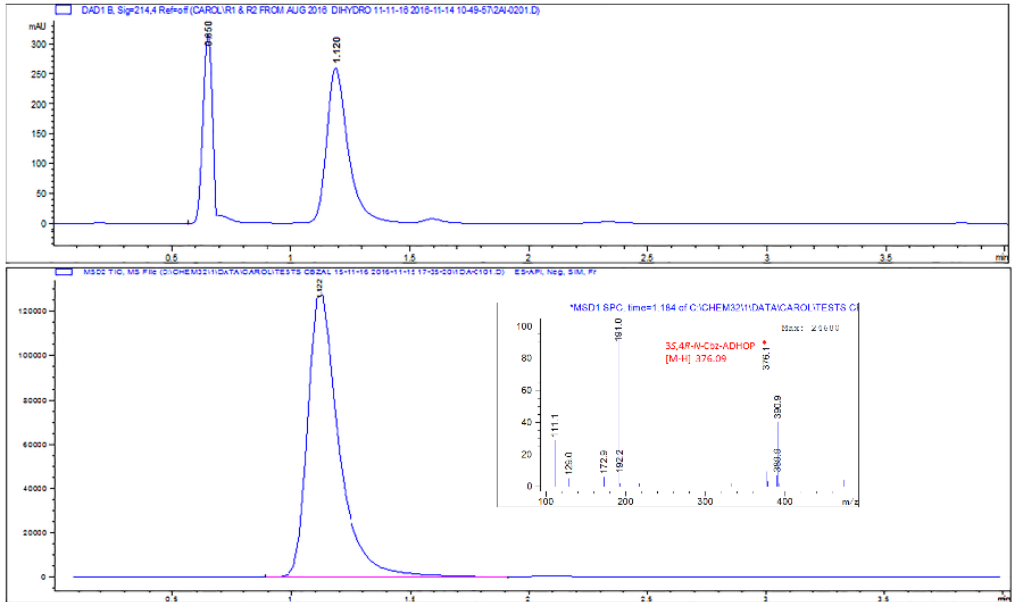

C

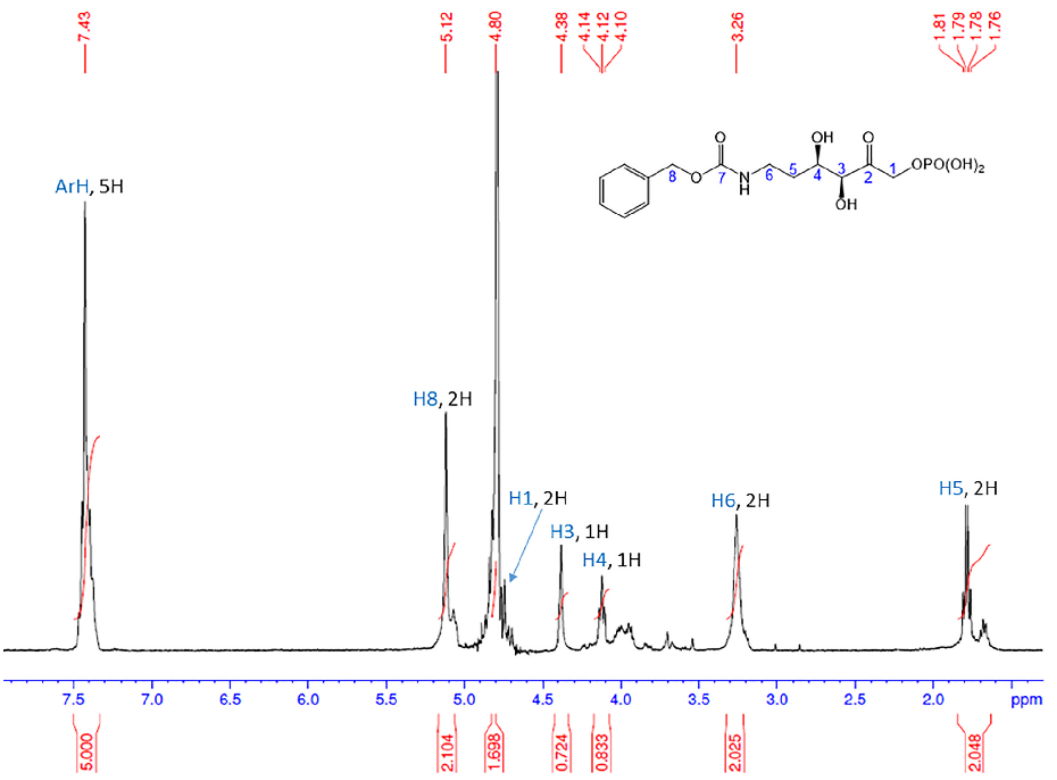


bioRxiv preprint doi: https://doi.org/10.1101/568972; this version posted March 5, 2019. The copyright holder for this preprint (which was not certified by peer review) is the author/funder, who has granted bioRxiv a license to display the preprint in perpetuity. It is made available under aCC-BY-NC-ND 4.0 International license.

Supplementary Figure 6. HPLC and HPLC-MS traces and spectra for all components quantified to measure the conversion of glycerol and aldehydes into chiral aldol products. a, HPLC separation and mass spectrometry identification of glycerol-3-phosphate (G3P) and dihydroxy acetone phosphate (DHAP). The dominant selected ions identified here $\left(\mathrm{m} / \mathrm{z} 171^{-}\right.$for G3P and $\mathrm{m} / \mathrm{z} 169^{-}$for DHAP) were then used for SIM analyzes of subsequent reactions. $\mathbf{b}, \mathrm{HPLC}$ separation of $\mathrm{N}$-Cbz-3-aminopropanal and $N$-Cbz-3S,4R-ADHOP showing absorbance $A_{214 n m}$ (upper panel) and mass spectrometry identification of $\mathrm{N}$-Cbz-3S,4R-ADHOP (inset). c, the authenticity of $\mathrm{N}$-Cbz-3S, $4 R$-amino-3,4-dihydroxy2-oxyhexyl phosphate ( $N$-Cbz-3S,4R-ADHOP) produced by the nanofactory was confirmed by ${ }^{1} \mathrm{H}$-NMR analysis of $\mathrm{N}$-Cbz-3S,4R-ADHOP prepared by reaction of commercially available $\mathrm{N}$-Cbz-3aminopropanal and DHAP catalysed by FruA, and isolated by HPLC.

(1)

2

